NISTIR 5547

\title{
AN ALGORITHM TO DESCRIBE THE SPREAD OF A WALL FIRE UNDER A CEILING
}

Henri E. Mitler

Building and Fire Research Laboratory

Gaithersburg, Maryland 20899

QC

100

U56

N0. 5547

1994

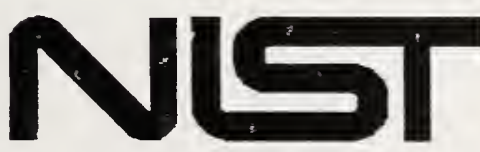

I Inited States Department of Commerce unology Administration onal Institute of Standards and Technology 


\section{AN ALGORITHM TO DESCRIBE THE SPREAD OF A WALL FIRE UNDER A CEILING}

Henri E. Mitler

November 1994

Building and Fire Research Laboratory

National Institute of Standards and Technology

Gaithersburg, MD 20899

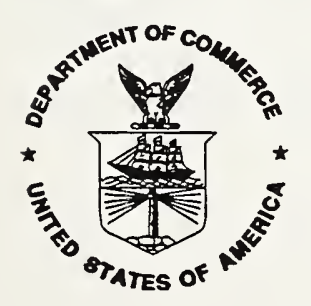

\section{U.S. Department of Commerce}

Ronald H. Brown, Secretary

Technology Administration

Mary L. Good, Under Secretary for Technology

National Institute of Standards and Technology

Arati Prabhakar, Director 



\section{TABLE OF CONTENTS}

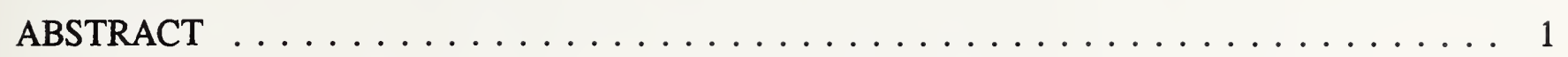

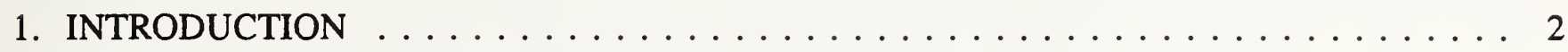

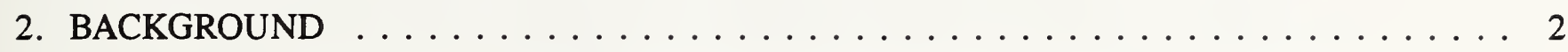

3. EFFECTS OF THE PRESENCE OF A CEILING $\ldots \ldots \ldots \ldots \ldots \ldots \ldots$

3.1 Flame Tips Below the Ceiling $\ldots \ldots \ldots \ldots \ldots \ldots \ldots \ldots \ldots$

3.2 Flame Length Greater Than The Wall Height . . . . . . . . . . . . 3

3.3 Ceiling Ignition and Downward Flame Spread . . . . . . . . . . . . . 4

3.4 Other Effects . . . . . . . . . . . . . . . . . . . . 4

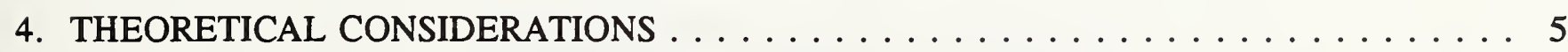

4.1 Effects of Trapped Gas Layer and Hot Ceiling . . . . . . . . . . . . 5

4.2 Flow Patterns of the Thermal Plume . . . . . . . . . . . . . 5

4.3 Radiation Feedbacks . . . . . . . . . . . . . . . . . . . . . 10

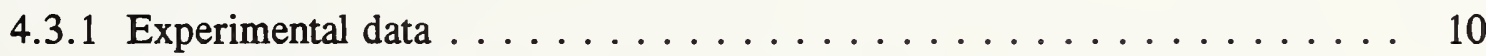

4.3.2 Theoretical calculations of fluxes $\ldots \ldots \ldots \ldots \ldots \ldots \ldots \ldots$

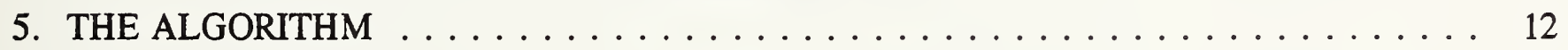

5.1 What Is Needed For The Algorithm . . . . . . . . . . . . 12

5.2 A First Approximation . . . . . . . . . . . . . . . 12

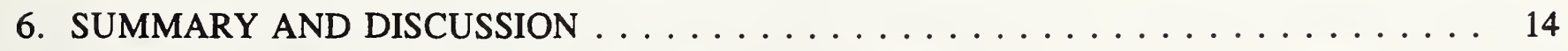

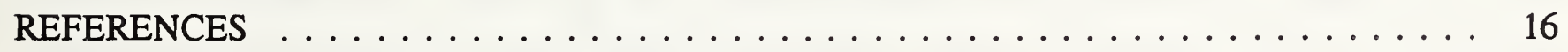

NOMENCLATURE . . . . . . . . . . . . . . . . . . . . . . . . . 19

Appendix A. Experimental Data . . . . . . . . . . . . . . . 21

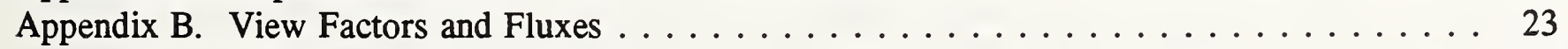

Appendix C. The Program SPREAD . . . . . . . . . . . . . . . . . . . . . . . 29

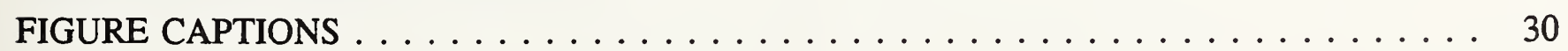





\title{
AN ALGORITHM TO DESCRIBE THE SPREAD OF A WALL FIRE UNDER A CEILING
}

\author{
Henri E. Mitler \\ Building and Fire Research Laboratory \\ National Institute of Standards and Technology
}

November, 1993

\begin{abstract}
After some discussion of wall fires, the effects that a ceiling has on a wall fire are analyzed and discussed qualitatively. There are two kinds of effects: first, when the upper sill of the ventilating opening lies below the ceiling (as is usual), a layer of hot gas is trapped, which heats the walls by convection and radiation; the heated ceiling also radiates to the walls. A calculation which uses the wall-fire computer model SPREAD is carried out to demonstrate how these effects can be calculated now. Second, when the flame impinges on the ceiling, it bifurcates and spreads horizontally, rather than vertically. A simple algorithm is presented which calculates the spread rate of these horizontal flame extensions, as well as the modified pyrolysis rate, due to the modified radiation feedbacks.
\end{abstract}

Key words: algorithm; ceilings; ceiling fires; computer models; fires; fire growth; fire spread; SPREAD; wall fires 


\section{INTRODUCTION}

Wall fires are significant for two related reasons: first, because fires spread upward swiftly on vertical surfaces, often leading to rapid flashover in rooms. Second, the upward spread rate, especially in a corner, is a sensitive function of the flammability of the material. Therefore it can be used to estimate its flammability. Indeed, full-scale corner tests have been developed to assess the fire hazards of material linings.

Accurate modeling of wall fires will enable the flammability and hazard of wall-covering materials to be assessed from bench-scale tests of the materials, rather than having to rely on more expensive and time-consuming full-scale tests. Also, such a modeling capability will allow the determination of the interactions among fuel packets (e.g., items of furniture), the enclosure, and flame spread along combustible walls and ceilings.

Our inability to predict these interactions accurately has led to difficulties, such as confusion in the interpretation of European and American corner room fire tests. The EUREFIC test (ISO 975; see Proceedings, 1991), which evaluates interior lining materials, is a corner test where the walls and ceiling are both lined with the same material. The corner tests used in the USA (ASTM; UBC Standard 42-2) do not have the ceiling lined. The results can be very different with the two tests (Sumathipala, 1993). It would be very useful to come up with a model which can cover both cases.

\section{BACKGROUND}

A number of studies of wall fires have been made, and several wall-fire models created to simulate the ignition and upward spread of wall fires. For studies, see Ahmad and Faeth (1979), Hasemi (1986), Orloff et al (1975, 1977, 1979), for example. For models, see Saito et al (1985), Mitler (1986, 1988, 1990), Quintiere et al (1986), Delichatsios (1987), Chen et al (1993), Brehob and Kulkarni (1993), etc. NIST has developed reasonably successful models which simulate/predict wall fires and upward flame spread under unconfined (no-ceiling) conditions (Mitler, 1989, 1990; Steckler and Mitler, 1988). The model name is SPREAD.

Most of these studies, however, have ignored the effect(s) of the ceiling. Thus, most extant models assume (in effect) that the wall is infinitely high. In fact, the presence of a ceiling has several important consequences, and the effect(s) of the ceiling on room fires is one of the most notable missing pieces in our ability to accurately predict the development of room fires.

Friedman (1975) reported that radiative feedback from a hood tripled the burning rate of a PMMA pool fire, compared to its burning in the open. Hinkley et al (1969-84) examined flames spreading under a corridor ceiling, and their substantial effect on the ignition of floor samples, among other things. Alpert et al (1981) studied wall fires spreading into a corridor-like ceiling channel, similar to Hinkley's. These experiments demonstrated that wall burning rates in confined spaces increased significantly over open-burning rates. While large-scale experiments on flame extensions has been done by Gross (1989) for axisymmetric and corner fires with noncombustible ceilings, and by Kokkala (1991) for axisymmetric fires, no work has been reported for extensions against a flat wall with a ceiling. 
Mitler and Steckler (1993) reviewed the literature, quantified the effect (in part), and demonstrated the importance of the ceiling on the development of enclosure fires. The conclusion was that ceilings do eed have significant effects on the development of fires in enclosures. Thus, as has been demonstrated by these authors, the effects of ceilings on the progress of a compartment fire are substantial, and need to be included in any compartment wall-fire calculations. Although the available studies address various aspects of the ceiling-fire problem, they collectively do not provide a minimally complete set of data (e.g., flame shape, thickness, temperature distribution, heat flux, etc.), for the development and validation of a wallceiling or corner-ceiling fire algorithm.

\section{EFFECTS OF THE PRESENCE OF A CEILING}

\subsection{Flame Tips Below the Ceiling}

The most obvious effect of the presence of a ceiling is the development of a hot, smoky, and oxygen-vitiated layer under the ceiling. This layer increases the heat fluxes to various surfaces in the room. The added heat flux to the already-pyrolyzing regions of a burning wall accelerates the burning and spread rates. The added heat flux to the preheating region accelerates the spread rate still further. This is illustrated by the schematic drawing in figure 1. This occurs even before the flame "splashes" against the ceiling; when the flame is longer, additional effects come into play, as described in the next subsection.

\subsection{Flame Length Greater than the Wall Height}

When the wall flame reaches the ceiling, it splashes, and the flame "extension" is forced to move at right angles to its previous trajectory. Part of the flame extension may be an oval or other shape, projected on the ceiling, as shown in figures 2 and 3. Because of that, the view factors for radiation feedback from this part of the flame to both the pyrolyzing and the preheating sections of the wall are increased; this is indicated in figure 4. This enhancing effect is in addition to the extra flux from the hot gas layer, discussed above. The burning as well as the upward spread rates of the wall fire will thus be further accelerated.

As soon as the pyrolysis front reaches the ceiling, "upward" spread must be reinterpreted as concurrent-flow spread (in the horizontal direction), and the rates will depend on the geometry and configuration of the enclosure and the resulting flows and embedded flames. These can be quantitatively calculated, once we know the length and shape of the flame extensions.

Experiments have demonstrated that the flame moves out along the wall/ceiling intersection, as shown in figure 3, rather than continuing to move in a direction as close as possible to the previous (upward) direction, as shown in figure 2, or fanning out across the ceiling as a semicircle, as is indicated in figure 5. The reason it does this is probably because of the formation of vortices, as first hypothesized by Williamson et al (1984), and demonstrated for the corner fire by Satoh (1989). 
Quintiere (1988) described an experiment carried out by B. Lee in 1988 (see Figure 6). The back wall of an ASTM enclosure $(2.44 \times 3.56 \times 2.44 \mathrm{~m}$-- i.e., $8 \times 12 \times 8$ feet -- see Anon., 1983, 1993) was partially covered by $6.35 \mathrm{~mm}$-thick (1/4") sheets of PMMA in the shape of a "T." The bottom was $1.22 \mathrm{~m}\left(4^{\prime}\right)$ wide, and the cross-bar above was $1.22 \times 2.44 \mathrm{~m}\left(4^{\prime} \times 8^{\prime}\right)$; (the results would probably not have been any different if the entire wall had been covered). It is important to note the flaming "arms" which develop along the wall-ceiling intersection (they appear to lie principally against the wall). These arms, or "extensions," have the length $\ell_{\mathrm{e}}$ and width $\delta$ (the thickness will be discussed later) -- see Figure 7. Predicting the further rate of spread of the fire depends in part on knowing $\delta$ and $\ell_{\mathrm{e}}$. In order to calculate the length and shape of the flame extensions, the new view factors, and the consequent accelerated preheating and subsequent advance of the pyrolysis front, it is necessary to understand quantitatively the flow of the thermal plume.

Cleary and Quintiere (1991) have developed a wall/ceiling-fire model based on the Lee experiments. They simplify the problem by assuming that the width $\delta$ of the arms is $w / 2$, where $\mathrm{w}$ is the width of the wall fire; they also assume that there is, additionally, a semicircular flame zone against the ceiling, as shown in figure 5. This formulation is limited, and leads to at least one quantitatively incorrect conclusion: if $\mathrm{w}>2 \mathrm{~h}_{\mathrm{w}}$, then $\delta>\mathrm{h}_{\mathrm{w}}$. That is, the width of the flame extension is greater than the height of the wall.

\subsection{Ceiling Ignition and Downward Flame Spread}

In order to model wall/ceiling flame spread more completely, consideration must also be given to two other phenomena: first, the effects of the ignition of a combustible ceiling. Second, the downward spread of the fire; although this is counter-flow spread, just like the lateral spread of the wall fire, it has been observed to be much more rapid than the latter (Karlsson 1989, 1992).

Small-scale experimental work on burning and spread rates across (channeled, two-dimensional) combustible ceilings has been done by Atreya (Atreya and Mekki, 1992) for laminar flames and by Pello for turbulent as well as laminar flames; the latter, for combustible ceilings. One of Pello's observations is that the onset of turbulence shortens the flames, presumably because mixing with ambient air is enhanced, permitting faster and more efficient combustion (Zhou, 1992).

In order to establish predictive algorithms to describe the above effects correctly in a model, we need to develop a quantitative understanding of fluid flows, entrainment, and combustion processes at and under the ceiling, upon the impingement of the flames on the ceiling.

\subsection{Other Effects}

Another effect is one observed by Saito (1993) for corner fires: he carried out a number of corner fire experiments with a burner and inert walls; for the same rate of heat release, the heat fluxes to the wall and the resultant wall temperatures, in the steady state, were smaller when a 
ceiling was placed over the corner, contrary to what one's intuition would have predicted. His tentative explanation for the phenomenon is that the "back pressure" from the ceiling slows the upward flow of the thermal plume, resulting in a smaller heat transfer coefficient and therefore in a lower convective heat transfer to the wall, at least in the lower portions of the flame.

\section{THEORETICAL CONSIDERATIONS}

\subsection{Effects of Trapped Gas Layer and Hot Ceiling}

We now discuss the first of the effects discussed in Section 3. This part of the ceiling effect can be theoretically calculated (i.e., modeled) now, in fact, for the "early" stages of a wall fire, before the flame has impinged on the ceiling. The procedure is straightforward, though (at present) awkward. This is done as follows: the upward spread of a fire on a wall of height $h_{w}$ is calculated; it is done here with the program SPREAD. This yields, among other things, the rate of heat release from the slab/wall. This power output is then used as an input to a roomfire program (FIRST (Mitler and Rockett, 1987) was used for this purpose). The latter then yields the ceiling and upper-layer gas temperatures as a function of time, and the resulting convective and radiative heat fluxes back to the wall. The original upward-spread program (SPREAD, again) is then rerun with those fluxes as input. This results in enhanced growth and spread rates. Note: even if SPREAD does not give exact answers, it will act as a baseline, and the work to be given will show, with reasonable accuracy, the departures from those baseline results.

As an example, curve NC in figure 8 shows the power output from a 2-foot-wide, 8 -foot-high slab of PMMA, ignited at the bottom, as a function of time (this includes the RHR from the igniter). Ignition occurs at $t=198 \mathrm{~s}$; the top of the slab is reached at $t=677 \mathrm{~s}$, and the RHR there is $315 \mathrm{~kW}$. The RHR continues to increase slowly thereafter. In curve C, the results of the first iteration of the procedure described above is shown; it is seen that ignition occurs about 20 seconds earlier, at $t=178$, and that the upward spread rate is higher: the top of the slab is reached about 170 seconds earlier, at $t=504$, and the RHR at that moment is $350 \mathrm{~kW}$. Incidentally, that, in turn, means that the RHR used in FIRST should be the enhanced rates. Proceeding in this way, one (should) iterate to convergence.

Note that a room-fire model uses the correct ceiling height, whereas SPREAD implicitly assumes a ceiling so high that the flames never impinge on it. The procedure indicated above will be carried out automatically, without the need to iterate back and forth, once SPREAD is embedded into a room-fire model. SPREAD is the "test-bed" prototype program.

\subsection{Flow Patterns of the Thermal Plume}

Additional effects arise from radiative feedback from the flames under the ceiling. The dashed curve in figure 9 indicates schematically how the further (lateral) extension of the fire along the 
arms on the wall would accelerate the RHR curve even more. In order to calculate this feedback, one must calculate the view factors. But in order to do that, it is necessary to know the positions and areas of the flame extensions. Since the flames will follow the thermal plume flows, the first task is to determine what the flows are.

Referring to figure 3, we see that there must be hot gas flow along the arms. Indeed, it is appropriate here to point out that the gas flows are not intrinsically visible; their existence is inferred from simple mass and momentum conservation. Their shape(s), location, and direction become evident only when they transport a visible component, such as particles or luminous flames.

There probably is a ceiling jet as well, though it is not evident because it does not carry along much (if any) flame. This bifurcation of the flow into arms and into a ceiling jet is expected to be approximately independent of the existence of combustion in the gas phase (except insofar as combustion gives rise to buoyancy).

For the moment we will assume that the arms are contiguous with the wall only. That is, except for the thickness of the (flame) arms, there is no part of the arms which is in contact with the ceiling. This is, of course, subject to experimental verification.

The upward mass flow rate in the plume at any height $\mathrm{x}$ is

$$
\dot{m}(x)=w v(x) \rho_{g}(x) \theta(x)
$$

where $w$ is the width of the plume, $\rho_{\mathrm{g}}$ its density, $\theta(\mathrm{x})$ is the thickness of the plume at the height $\mathrm{x}$, and $\mathrm{v}(\mathrm{x})$ the (mean) velocity across the plume at $\mathrm{x}$,

$$
\mathrm{v}(x) \equiv \frac{1}{w \theta(x)} \int_{0}^{\theta(x)} d z \int_{-w / 2}^{w / 2} \mathrm{v}(x, y, z) d y
$$

Then at the ceiling, the upward mass flow of the plume is

$$
\dot{m}_{c}=w \mathrm{v}_{c} \rho_{g c} \theta_{c}
$$

where the subscripts " $\mathrm{c}$ " indicate that the various quantities are evaluated at the Ceiling. A fraction $\mathrm{F}$ of the flow $\dot{\mathrm{m}}_{\mathrm{c}}$ continues along the ceiling, away from the wall (that is, in the direction $\mathrm{z}$, orthogonal to $\mathrm{x}$ and $\mathrm{y}$ ); we refer to this fraction, as before, as the ceiling jet; we may also refer to it as "the central jet." The remainder (the fraction $1-F$ ) goes off along the wall-ceiling intersection. Again as before, we call the latter jets the "arms," or "extensions" (see Figure 7), of width $\delta$ and length $\ell_{\mathrm{e}}$. In Eqs.(13) to (15), below, we take the width of the central jet to be $w_{j}$, analogous to $\delta$ for the arms. The analogue to the arm length $\ell_{e}$ is the central jet length "a," discussed in the section on radiation feedback.

We assume that there is a negligible loss of energy from the turn at the ceiling; hence the horizontal flow speed must be largely unchanged from the upward speed at the ceiling, $v_{c}$. 
Assuming no discontinuity in the thickness of the flow, the thickness of the arms where they join the upward-moving plume, $\theta_{\mathrm{a}}$, is the same as $\theta_{\mathrm{c}}$. Finally, assuming the density of the gas constituting the arms also to be unchanged, the mass flow along the arms must be

$$
\dot{m}_{a}=(1-F) \dot{m}_{c}=2 \delta \theta_{c} \mathrm{v}_{c} \rho_{g}=\frac{2 \delta}{w} \dot{m}_{c}
$$

Thus,

$$
\mathrm{F}=1-2 \delta / \mathrm{w}
$$

It is also clear from Eq.(4) and from symmetry that we can never have the sum of the widths of the arms greater than the width of the plume; that is,

$$
\delta \leq w / 2
$$

We now obtain an approximate expression for $\delta$ as a function of w. Since little experimental data on flows exists, we will infer as much as possible from symmetry arguments. First, consider the behavior of the hot gases across the ceiling, when the wall and the fire are both extremely wide (that is, $w>>h_{w}$ ) -- this is illustrated in figure 10; the wavy upwardlypointing arrows at the top indicate the flow of the hot product gases (the ceiling jet). It is clear from symmetry that away from the edges of the fire, the flow must be nearly two-dimensional, as if the ceiling jet were traveling down a corridor; thus, $\mathrm{F}$ approaches unity. Note that we have omitted showing the arms, in figure 10.

We evidently must always have $\delta \leq \mathrm{h}_{\mathrm{w}}$. Then, assuming that the thickness of the arms is the same as the (local) thickness of the plume $\left(\theta_{\mathrm{a}}=\theta_{\mathrm{c}}\right)$, and that the speed of the flow does not change at the turn, then for the case $\mathrm{w}>2 \mathrm{~h}_{\mathrm{w}}$, we must have $\delta<\mathrm{w} / 2$; the "excess" must travel along the ceiling, orthogonal to the arms.

We know from the experiments carried out by B. Lee and others (figure 6) that there will be some flow down the two arms, as shown in figure 7; that is, $F<1$. In light of that, consider the opposite extreme: a very narrow fire, as shown schematically in figure 11. Assuming that the flame always spreads laterally along the wall-ceiling intersection, there are two possibilities:

a) besides the flow along the two arms, a narrow tendril of gas continues along the ceiling; this may spread out radially into a fan, or behave some other way.

b) there may be no such flow, until some critical width $w_{c}$ is achieved. If that were so, then for w slightly greater than $w_{c}$, a "tendril" of gas begins to escape.

Finally, for an intermediate-width fire, we must have a mixed regime, where there is definitely some flow along the ceiling, besides that along the arms, as shown in figure 7.

We now try to express these points in an explicit relationship. When $w$ is very narrow, it is clear that $\delta$ must be small. For larger $\mathrm{w}$, on the other hand, the vertical width $\delta$ of the extension is (most likely) only weakly dependent on the horizontal width $w$ of the original flame. We 
assume that to be the case. Thus, we might expect a dependence for $\delta(w)$ such as is given by the following simple expression which satisfies the above observations for all three cases (w narrow, intermediate, and wide):

$$
\delta(w) \approx A\left[1-e^{-p w}\right]
$$

where A and p are to be determined. To this end, we note that Alpert (1975) found that the initial ceiling-jet thickness for an axisymmetric plume is 5 to $8 \%$ of the room height. Motevalli and Marks (1991) found that the thermal boundary layer approaches $11.2 \%$, asymptotically, for some small, axisymmetric fires. For a corner fire, Karlsson and Magnusson (1990) found the thickness to be $5 \%$ of the room (ceiling) height, while Quintiere (1993) took it to be $8 \%$ of the room height. "Room height" may be interpreted as "fire-surface to ceiling" height.

If $\delta(w)$ is given by Eq. (7), then (5) yields

$$
F=1-\frac{2 A}{w}\left(1-e^{-p w}\right)
$$

It is clear that as w approaches zero, F must go to some constant value which is nonnegative and no greater than 1:

$$
0 \leq 2 \mathrm{Ap} \leq 1 \text {. }
$$

If $\mathrm{A}<1 /(2 \mathrm{p})$, the result is shown as curve $\mathrm{A}$ in figure 12. For the case that $\mathrm{F}$ approaches zero as $w$ approaches zero, $A=1 /(2 p)$, and

$$
F=1-\frac{1-e^{-p w}}{p w}
$$

This is shown as curve $B$ in figure 12 .

On the other hand, it is possible (as discussed earlier) that until some critical width $\mathrm{w}_{\mathrm{c}}$ is achieved, there is no contribution to the central jet. If this is in fact the case, i.e., if $F=0$ for $\mathrm{w}<\mathrm{w}_{\mathrm{c}}$, then we must have

Finally, for $w>w_{c}$, we must have

$$
\delta=w / 2 \quad \text { for } \quad w<w_{c} \text {. }
$$

$$
\delta<\mathrm{w} / 2 \text {. }
$$

That is, if there indeed exists a critical width $\mathrm{w}_{\mathrm{c}}$, then

$$
\delta=\left\{\begin{array}{cc}
w / 2 & w \leq w_{c} \\
<w / 2 & w>w_{c}
\end{array}\right.
$$

The simplest such approximation is 


$$
\delta= \begin{cases}w / 2 & w \leq w_{c} \\ w_{c} / 2 & w \geq w_{c}\end{cases}
$$

although it is certainly possible to have

$$
\mathrm{w}_{\mathrm{c}} / 2<\delta<\mathrm{w} / 2 .
$$

This dependence is shown as the solid curve in figure 13, and from Eq.(5), the dependence of $\mathrm{F}$ on $\mathrm{w}$ would be

$$
F= \begin{cases}0 & w<w_{c} \\ \frac{w-w_{c}}{w} & w \geq w_{c}\end{cases}
$$

as shown in curve $\mathrm{C}$, figure 12. The initial slope of the solid curve in Figure 13 is 0.5 . The dashed curves in that figure correspond to Eq.(7): the upper dashed curve corresponds to Ap $>0.5$ while the lower dashed curve corresponds to Ap $<0.5$.

Since a fraction of the flow has been detoured into the arms, the initial width of the ceiling jet may be smaller than $w$. It will surely be so, if its thickness is the same as the thickness $\theta_{c}$ of the plume at the ceiling. The more general assumption is that the ceiling jet will either start at or expand to, some width $\mathrm{w}_{\mathrm{j}}$, such that its thickness is $\Delta$ (obtained experimentally or via some other argument), rather than $\theta_{c}$. We then have, for the ceiling jet,

$$
F \dot{m}_{c}=w_{j} \mathrm{v}_{c} \rho_{g c} \Delta
$$

and Eq.(4) implies

$$
w_{j}=\frac{F \dot{m}_{c}}{\mathrm{v}_{c} \rho_{g, c} \Delta}=F w \theta_{c} / \Delta
$$

We therefore need to find $\mathrm{F}$ as a function of $\mathrm{w}, \mathrm{h}_{\mathrm{w}}$, and the total power output of the fire, $\mathrm{Q}$. We can express it in terms of $w$ by using Eq.(5); then Eq.(14) becomes

$$
w_{j}=w \frac{\theta_{c}}{\Delta}\left(1-\frac{2 \delta}{w}\right)=\frac{\theta_{c}}{\Delta}(w-2 \delta)
$$

It is possible, as discussed earlier, that the flow for the central ceiling jet fans out radially from its initial width (at the ceiling) of $w_{j}$.

In order to discuss the phenomena involved, precisely, refer to figure $14 \mathrm{a}$, a schematic of the appearance of wall-fire flames which strike the ceiling once the pyrolysis zone has extended 
beyond $z=h_{w}$. The ceiling is allowed, in imagination, to be swung upward as if it were hinged at its intersection with the wall. The pyrolyzing areas are indicated by the unprimed letters, and the preheating areas, by primed letters. Thus, A, B, and C are the pyrolyzing areas (and A" as well), while A', B', and C' are preheating areas. Figure 15 shows a few more details.

Then consider the case illustrated in figure 4; that is,

$$
\mathrm{x}_{\mathrm{p}}<\mathrm{h}_{\mathrm{w}}<\mathrm{x}_{\mathrm{f}}
$$

Then the flames in Section C' ( $C$ being nonexistent for an inert ceiling) irradiate $A "$ ", both in the pyrolyzing and in the preheating sections. Thus, enhanced power outputs and enhanced spread rates are to be expected.

Although there has been preheating in the region under the extensions, that heating is sufficient to permit lateral growth along the arms (sections B) only when $x_{p}$ reaches $h_{w}$.

We next need to discuss the view factors. This is sufficiently complex that a separate section is devoted to it.

\subsection{Radiation Feedback}

\subsubsection{Experimental data}

The most nearly relevant experimental data are from Hinkley et al (1984). Some of their results are given in Appendix A. Not all of the data given there will be used in this paper. However, it is important that the functional form of the fluxes be shown. Moreover, it is important that we note the observations made by Hinkley et al on ignition of and spread of fire over the floor, as an indication of the importance of the ceiling radiation feedback. Finally, these data will be used in our subsequent studies.

With their configuration, the peak flux to the ceiling was $170 \mathrm{~kW} / \mathrm{m}^{2}$. The peak downward flux was $150 \mathrm{~kW} / \mathrm{m}^{2}$; this is high enough to ignite most combustible materials within a few seconds. Hinkley et al assumed that there was a wood floor; they found that the flux was sufficiently intense that the floor would ignite and that the resulting fire would spread. They carried out the calculation for several assumed ceiling types, including a non-combustible, perfectly insulating ceiling; an asbestos ceiling; and several types of flammable ceilings. For the non-flammable as well as for several of the flammable ceilings, the results were very similar to the results that are observed for the spread of flame on a vertical wall: for wood materials, the upward spread ceases beyond a certain point; the pyrolysis front attains an asymptotic value. (For some other flammable ceilings, the downward flux is so high that spread continues and even accelerates). Whether either of these behaviors could occur for a vertical flame alone is doubtful. 


\subsubsection{Theoretical calculations of fluxes}

The radiation feedback from the arms to the wall (region $\mathrm{A}$ " in figure 14b) is small, since the flames are largely in the same plane. Moreover, their contribution is not very different from what it would be from the flames above A", if the flames extended vertically, as in figure 14b. Therefore the additional fluxes seen by the pyrolyzing and preheating wall in the original $\mathrm{v}$ ertical section, as well as in the arms, arise mostly from the flame region $\mathrm{C}, \mathrm{C}^{\prime}$ on the ceiling (see figure 14a). The radiation from $\mathrm{A}^{\prime \prime}, \mathrm{B}$, and $\mathrm{B}^{\prime}$ to $\mathrm{C}$ and $\mathrm{C}^{\prime}$ is only relevant for flammable ceilings. Since we are limiting ourselves to inert ceilings for the present, it is not necessary to calculate them.

The radiation feedback from the flame on the ceiling (the areas $C$ and $C^{\prime}$ in Figure 14a, or the area $A_{2}$ in figure 17) ) to the original vertical wall sections ( $A^{\prime \prime}$ in Figure 14b) and to the arms (areas B, B' in Figure 14a) are calculated in Appendix B. Note that with the assumption that the shaded parts of $A$ and $A^{\prime}$ in figure $14 b$ correspond to $B$ and $B^{\prime}$ in figure 14a, the unshaded parts of $A$ and $A^{\prime}$ correspond to $C$ and $C^{\prime}$ in 14a. The power supplied to the lower part of the wall is given by

$$
\dot{E}_{L} \approx \frac{\phi_{r m} b^{2}}{\pi}\left(Y_{m}-Y_{i}\right)\left[\tan ^{-1} \frac{1}{Y}-\frac{\bar{Y}}{r} \tan ^{-1} \frac{1}{r}+\frac{\bar{Y}}{2} \ln \left\{\frac{\left(1+\bar{r}^{2}\right) \bar{Y}^{2}}{\bar{r}^{2}\left(1+\bar{Y}^{2}\right)}\right\}\right]
$$

where $Y_{i}$ corresponds to the normalized thickness of the hot layer and $Y_{m}$ corresponds to the room height. These and the other symbols are defined in the Appendix. The mean radiation flux from the ceiling-jet flame is given by

$$
\phi_{r m} \approx \frac{\phi_{r}(0)}{\left(x_{f}-h_{w}\right) q}
$$

where $\phi_{\mathrm{r}}(0)$ is the downward radiation flux from the flame at the intersection of the wall and ceiling.

The power supplied to the upper part of the wall is given by

$$
\dot{E}_{U} \approx \frac{\phi_{r m} b^{2}}{\pi} Y_{i}\left[\tan ^{-1} \frac{1}{Y^{\prime}}-\frac{Y^{\prime}}{r^{\prime}} \tan ^{-1} \frac{1}{r^{\prime}}+\frac{Y^{\prime}}{2} \ln \left\{\frac{\left(1+r^{\prime 2}\right) Y^{\prime 2}}{r^{\prime 2}\left(1+Y^{\prime 2}\right)}\right\}\right]
$$

where $\mathrm{Y}^{\prime} \simeq \mathrm{Y}_{\mathrm{i}} / 2$ and $\mathrm{r}^{\prime}$ is given by Eq.(B32).

Finally, the mean flux falling at the distance $\mathrm{z}$ downstream on each of the arms (see figure 18) is, from Eq.(B36), 


$$
\phi_{a r m} \approx \frac{\phi_{r m}}{2 \pi}\left[\tan ^{-1}\left(\frac{z+b}{c}\right)-\tan ^{-1}\left(\frac{z}{c}\right)-\frac{c}{\sqrt{a^{2}+c^{2}}}\left(\tan ^{-1}\left(\frac{1}{r}\right)-\tan ^{-1}\left(\frac{1}{r_{1}}\right)\right]\right]
$$

where $\mathrm{r}$ is given by Eq.(B22) and $\mathrm{c}$ and $\mathrm{z}$ are given by Eq.(B35).

\section{THE ALGORITHM}

The most attractive approach for establishing an algorithm for the growth and spread of the fire along wall and ceiling would be to use a simple set of algebraic equations. Unless we are merely to use correlations, however, it is apparent that we must solve coupled differential equations which describe various rates. Indeed, a number of such analytic formulations of the upward spread process have been developed (see Saito et al 1985; Mitler 1986; Quintiere et al 1986). The most recent is due to Cleary and Quintiere (1991); however, they generally require simplistic approximations and limitations to be made. The alternative is to use a numerical approach, which can be more general and more powerful. This was done for the upward spread process, and the result was the program SPREAD (Mitler, 1990), which is described in Appendix C. As discussed above, one of the limitations of SPREAD is that it does not take the ceiling into account except in a limited way. We now describe how to overcome this deficiency.

\subsection{What is Needed for the Algorithm}

As indicated in the discussions above, we need to have the width, thickness, and length (extension) of the arms, as functions of the several independent parameters. The same is required for the central ceiling jet and the length and shape of that part of the flame. The heat fluxes and radiation view factors from the parts of the flames lying against the ceiling back to the ceiling and wall are also needed. A procedure was previously described to calculate the various view factors, Section 4.3. Other variables, such as $\delta, \ell_{\mathrm{e}}, \mathrm{y}_{\mathrm{e}}, \phi_{\mathrm{rm}}$, and a (in Figures 15 to 18 ) must be determined by making some simple assumptions.

\subsection{A First Approximation}

Consider the growth of the pyrolysis region. We wish to transform the calculations made by SPREAD for flame and pyrolysis front positions for $\mathrm{z}>\mathrm{h}_{\mathrm{w}}$ into the actual distributions (over the central jet, if any, plus along the arms).

Recall that Figure 14a is a schematic of the appearance of the fire, for the case that the pyrolysis zone has extended beyond $\mathrm{z}=\mathrm{h}_{\mathrm{w}}$. The areas marked $\mathrm{B}$ and $\mathrm{C}$ are the pyrolyzing areas, while B' and C' are the "preheating" regions where flame covers the surface but the latter has not yet 
reached the pyrolysis temperature. For a non-flammable ceiling, $\mathrm{C}$ has zero area, so that the dashed boundary between $\mathrm{C}$ and $\mathrm{C}^{\prime}$ would lie precisely at the wall-ceiling intersection.

Figure 14b shows the geometry implicit in SPREAD; again, $\mathrm{A}$ is the pyrolyzing area on the ceiling, $\mathrm{A}^{\prime}$ the preheating area, and $\mathrm{A}^{\prime \prime}$ is the pyrolyzing area on the wall.

For the zeroth-order approximation, we assume that the thickness of the plume flows along B,B' and $C, C^{\prime}$ in Figure $14 a$ are exactly the same as for $A, A^{\prime}$ in $14 b$; that is, in the notation of Section 4.2, $\theta_{\mathrm{a}}=\Delta=\theta_{\mathrm{c}}$. Then from mass conservation, the flow divides into $\mathrm{B}$ and $\mathrm{C}$ in proportion to their respective widths, as implied by Eq.(8). In other words, the extensions B, B' are just the same as the shaded parts of the areas $A$ and $A^{\prime}$ in figure $14 \mathrm{~b}$, of width $\delta$, while the region $\mathrm{C}, \mathrm{C}^{\prime}$ has the width $\mathrm{w}-2 \delta$.

We have assumed that the wall is flammable everywhere; the resulting rapid lateral spread of the arms across the wall translates, in this approximation, into continued vertical growth beyond $z=h_{w}$. The horizontal extensions (the arms) then are simply the shaded sections of $A+A^{\prime}$ in Figure $14 \mathrm{~b}$, turned through $90^{\circ}$. Thus their length is

and

$$
\ell_{\mathrm{e}}=\mathrm{x}_{\mathrm{f}}-\mathrm{h}_{\mathrm{w}},
$$

$$
\mathrm{y}_{\mathrm{e}}=\mathrm{w} / 2+\mathrm{x}_{\mathrm{p}}-\mathrm{h}_{\mathrm{w}}
$$

(see figure 15, which complements Figures 7 and 14).

If the ceiling is flammable, this is all straightforward. On the other hand, if the ceiling is inert, the situation is apparently inconsistent, since the pyrolyzing section $\mathrm{C}$ has zero extent, whereas B is finite. That is, the region beyond $z=h_{w}$ burns in the horizontal orientation, whereas it cannot, in the vertical orientation (since the ceiling is not flammable): the shaded parts of A and $\mathrm{A}^{\prime}$ in figure $14 \mathrm{~b}$ burn, the unshaded parts do not. The procedure which resolves this is to continue to calculate the flame height $x_{f}$ as if the entire region were in fact burning -- that is, use $\mathrm{Q}^{*}$ according to

$$
\dot{Q}^{*}=w H_{c} \int_{0}^{x_{p}} \dot{m}^{\prime \prime}(z) d z
$$

to find $x_{f}$, but then note that the actual power output is given by

$$
\dot{Q}=w H_{c} \int_{0}^{h_{w}} \dot{m}^{\prime \prime}(z) d z+2 \delta H_{c} \int_{h_{w}}^{x_{p}} \dot{m}^{\prime \prime}(z) d z
$$

That is, the length of $C$ is zero, that of $C^{\prime}$ is approximately constant at $x_{f}\left(t=t_{c}\right)-h_{w}$, where $t_{c}$ is the moment when the pyrolysis front on the wall arrived at the ceiling. Thus for a nonflammable ceiling, the calculated area $A$ must be multiplied by $2 \delta / w$ before adding that pyrolysis contribution to the rate of heat release. 
The procedure, then, is the following: we specify the slab height to be substantially greater than $h_{w}$. We then calculate $x_{p}(t)$ with SPREAD in the usual way. The program is modified, however, so that when $x_{f}>h_{w}$, we begin to calculate $\ell_{e}(t)$, according to Eq. (18) (as better expressions are found, they will be used in lieu. We must also calculate $\delta(t)$, according to Eqs. (7) or (11) (or another expression to be dictated by experiment, in the future). Finally, when $x_{p}$ grows beyond $h_{w}$, we must modify the expression for $Q(t)$, the time-dependent rate of heat release. This quantity is normally found in SPREAD by summing the mass-loss rates for all the horizontal strips into which the slab is divided, then multiplying the sum by the effective heat of combustion, $\chi_{\mathrm{A}} \mathrm{H}_{\mathrm{c}}$. For $\mathrm{x}_{\mathrm{p}}>\mathrm{h}_{\mathrm{w}}$, we must then multiply the mass-loss rate $\dot{m}_{j}$ for the strips $\mathrm{j}$ corresponding to $\mathrm{x}>\mathrm{h}_{\mathrm{w}}$, by $2 \delta / \mathrm{w}$, then sum.

Now consider the modifications that must be made in the zeroth-order process, due to the extra heating fluxes from the hot layer, hot ceiling, and flame feedback: the pyrolysis rate in region $\mathrm{A}^{\mathrm{N}}$ is enhanced by the hot layer fluxes and by the radiation from the orthogonal flame covering $\mathrm{C}, \mathrm{C}^{\prime}$. Likewise, the pyrolysis rate in the shaded part of the model region $\mathrm{A}$ is enhanced by radiation from $C, C^{\prime}$ to $B, B^{\prime}$. These fluxes are all relatively easily calculated from the expressions found above. The flames covering the regions $B$ and $\mathrm{B}^{\prime}$ contribute just about as much to $A^{\prime \prime}$ as the vertical parts $A, A^{\prime}$ would, were the wall indeed very high.

On the other hand, consider the differences in the two cases, for a moment. In the no-ceiling case, buoyancy continues to accelerate the gases (up to a point), whereas it decelerates in the arms (due to wall friction). For this and other reasons, entrainment into the arms will be at a different rate. Again, the heating fluxes from those flames back to the wall will probably be somewhat different from those calculated for the upward spread case. Finally, these will have to be consistent with experimental data. These and other corrections to the crude approximations made above, will be made next year.

If there exists a critical flow, then we expect something like Eq.(11) for $\delta$, whereas if there is no critical fiow, Eq. (7) would be more appropriate. When there will be relevant experimental data to appeal to, better expressions for $\ell_{\mathrm{e}}$ and for $\delta$ will be used.

Thus, the procedure is to increase the "external" fluxes impinging on $\mathrm{A}, \mathrm{A}$ ', and $\mathrm{A}$ " appropriately, calculate the resulting spread rate via SPREAD, take the appropriate fractions for the arms, and we are (in this simplest of approximations) done.

\section{SUMMARY AND DISCUSSION}

It has been demonstrated that the effects that a ceiling has on the progress of a room fire can be quite significant. We have described a number of these effects. It has been demonstrated that the heating effects of the hot layer (and hot ceiling) can already be taken into account with current models.

A "zeroth-order" algorithm has been formulated, which involves simple assumptions about the fluid flow and some straightforward, albeit complicated, expressions for the radiation feedbacks. 
It has been found that this can be implemented with an extension of the numerical approach currently used in SPREAD in order to describe the growth and spread of the fire under the ceiling is straightforward. We have also looked into the possibility of using some simple analytic formulation to do this, but such a formulation presents a number of problems.

Two effects have not been considered in developing this algorithm: combustion and spread in an oxygen-vitiated environment, such as is found under the ceiling, and the effect found by Saito (see Section 3.4). These should be investigated. 


\section{REFERENCES}

Ahmad, T., and Faeth, G.M. (1979) "Turbulent Wall Fires," in the 17th Symposium (International) on Combustion, The Combustion Institute, Pittsburgh, PA, p. 1149

Alpert, R.L. (1975) "Turbulent Ceiling Jet Induced by Large-Scale Fire," Combustion Science and Technology 11, p.197

Alpert, R.L., Mathews, M.K., and Modak, A.T. (1981) "Modeling of Ceiling Fire Spread and Thermal Radiation," FMRC Technical Report J.I. 0E0N8.BU, Factory Mutual Research Corp., Norwood, Mass.

Anon. (1983) "Proposed Method for Room Fire Test of Wall and Ceiling Materials and Assemblies," grey pages, 1983 Annual Book of ASTM Standards, Vol. 4.07; Amer. Soc. for Testing and Materials, Philadelphia, PA

Anon. (1993) "Standard Guide for Room Fire Experiments," ASTM-E603, Annual Book of ASTM Standards, Vol. 4.07; Amer. Soc. for Testing and Materials, Philadelphia, PA

Atreya, A. and Mekki, K. (1992) "Heat Transfer During Wind-Aided Flame Spread on a CeilingMounted Sample," 24th Symposium (International) on Combustion, The Combustion Institute, Pittsburgh, PA, p. 1677

Brehob, E. and Kulkarni, A.K., 1993. A Numerical Model for Upward Flame Spread with External Radiation. Annual Conference on Fire Research, National Institute of Standards and Technology, Gaithersburg, MD

Chen, Y., Delichatsios, M.A., and Motevalli, V. (1993) "Materials Pyrolysis Properties, Part I: An Integral Model for One-Dimensional Transient Pyrolysis of Charring and Non-Charring Materials," Combustion Science and Technology 88, p.309

Cleary, T.G., and Quintiere, J.G. (1991) "A Framework for Utilizing Fire Property Tests," in Fire Safety Science, Proceedings of the Third Int'l Symposium (Eds., G. Cox and B. Langford), Elsevier Applied Science, N.Y., p.64

Delichatsios, M.A. (1987) "A Simple Algebraic Model for Turbulent Wall Fires", in 21st Symposium (International) on Combustion; the Combustion Institute, Pittsburgh, PA, p.53

Fernandez-Pello (1992), personal communication

Friedman, R. (1975) "Behavior of Fires in Compartments," International Symposium on Fire Safety of Combustible Materials, University of Edinburgh, Centre for Industrial Consultancy and Liaison, October 1975, pp. 100-113.

Gross, D. (1989) "Measurement of Flame Lengths Under Ceilings," Fire Safety Journal 15, p.31

Hasemi, Y. (1986), "Thermal Modeling of Upward Wall Flame Spread", in Fire Safety Science (Proceedings of the First International Symposium); eds., C.E. Grant and P.J. Pagni; Hemisphere Publishing Corp., p.87 
Hinkley, P.L., Wraight, H.G.H., and Theobold, C.R., (1984) "The Contribution of Flames Under Ceilings to Fire Spread in Compartments," Fire Safety J. 7, No.3, p.227

Jones, W.W. (1985) "A Multicompartment Model for the Spread of Fire, Smoke, and Toxic Gases", Fire Safety Journal 9, No. 1-2, p.55

Karlsson, B., and Magnusson, S.E. (1990) "Room Fires and Combustible Linings," Chap. 33 in Fire and Polymers - Hazards Identification and Prevention (Editor, G.L. Nelson); Symposium Series 425, American Chemical Society, Washington, DC, p.566

Karlsson, B. (1992) "Modeling Fire Growth on Combustible Lining Materials in Enclosures," Report TVBB-1009, Dept. of Fire Safety Engineering, Lund University, Lund, Sweden (thesis)

Kokkala, M.A. (1991) "Experimental Study of Heat Transfer to Ceiling From an Impinging Diffusion Flame," in Fire Safety Science - Proceedings of the Third Int'l Symposium (Eds., G. Cox and B. Langford), Elsevier Applied Science, N.Y., p. 261

Kulkarni, A.K., Kim, C.I., and Kou, C.H. (1991) "Turbulent Upward Flame Spread for Burning Vertical Walls Made of Finite-Thickness, Practical Materials," Annual Report to NIST, May, 1991

Kulkarni, A.K., and Kim, C.I. (1992) "Turbulent Upward Flame Spread on Vertical Walls," submitted to Combustion and Flame

Mitler, H.E. (1986) "Exponential Spread Rate of Some Wall Fires," Ann. Conf. on Fire Research, National Bureau of Standards, Gaithersburg, MD, Nov. 1986

Mitler, H.E., and Rockett, J.A. (1987) "Users' Guide to FIRST, a Comprehensive Single-Room Fire Model", NBSIR 87-3595; National Bureau of Standards, Gaithersburg, MD

Mitler, H.E. (1988), "Algorithm for the Mass-Loss Rate of a Burning Wall", in Fire Safety Science Proceedings of the Second International Symposium (Eds., C.E. Grant and P.J. Pagni); Hemisphere Publishing Corp, p.179

Mitler, H.E. (1990) "Predicting the Spread Rates of Fires on Vertical Surfaces," 23d (International) Symposium on Combustion; The Combustion Institute, Pittsburgh, PA, p.1715

Mitler, H.E., and Steckler, K.D. (1993) "Comparison of Wall-Fire Behavior With and Without a Ceiling," NISTIR 5380, National Institute of Standards and Technology, Gaithersburg, MD, 20899

Mitler, H.E. and Steckler, K.D. (1994) "SPREAD - A Model of Flame Spread on Vertical Surfaces," NISTIR, in review

Motevalli, V., and Marks, C.H. (1991) "Characterizing the Unconfined Ceiling Jet Under Steady-State Conditions: A Reassessment," in Fire Safety Science - Proceedings of the Third Int'l Symposium (Eds., G. Cox and B. Langford), Elsevier Applied Science, N.Y., p.301

Orloff, L., de Ris, J., and Markstein, G.H. (1975), "Upward Turbulent Fire Spread and Burning of Fuel Surfaces," in 15th (International) Symposium on Combustion; the Combustion Institute, Pittsburgh, PA, p.183 
Orloff, L., Modak, A.T., and Alpert, R.L. (1977), "Burning of Large-Scale Vertical Surfaces", in 16th International Symposium on Combustion; the Combustion Institute, Pittsburgh, PA, p.1345

Peacock, R.D., and Bukowski, R.W. (1990) "A Prototype Methodology for Fire Hazard Analysis," Fire Technology, 26: 1, pp. 15-40.

Proceedings of EUREFIC Seminar (1991) Interscience Communications Ltd., London. Also available from Technomic Publishing, Lancaster PA

Quintiere, J.G., Harkleroad, M., and Hasemi, Y. (1986) "Wall Flames and Implications for Upward Flame Spread", Comb. Sci. and Tech. 48, p.191

Quintiere, J.G. (1988) "State of Fire Research and Safety," in Fire Safety Science, Proceedings of the Second International Symposium; Hemisphere Publishing Co., Washington, D.C., p.15

Quintiere, J.G. (1993) "A Simulation Model for Fire Growth on Materials Subject to a Room-Corner Test," Fire Safety Journal 20, p.313

Saito, K., Quintiere, J.G., and Williams, F.A. (1985), "Upward Turbulent Flame Spread", Fire Safety Science - Proceedings of the First International Symposium (Eds., C.E. Grant and P.J. Pagni); Hemisphere Publishing Corp., p.75

Saito, K. (1993) Grant progress report; to be published

Satoh, K. (1989) "A Numerical Study of Ceiling Jets Based on "T" Pattern Flames," in Fire Safety Science - Proceedings of the Second International Symposium (Eds., C.E. Grant and P.J. Pagni); Hemisphere Publishing Corp., p.159.

Siegel, R., and Howell, J.R. (1981) Thermal Radiation Heat Transfer, 2nd ed., McGraw-Hill, N.Y.

Steckler, K.D., and Mitler, H.E. (1988) "Experimental Study of the Pyrolysis Rate of a PMMA Wall Panel in a Reduced-Scale Enclosure," Combustion Institute/Eastern States Section; Chemical and Physical Processes in Combustion; Technical Meeting, Clearwater Beach, Fla., 73/1-4 pp., Dec. 1988

Sumathipala, K., Kim, A., and Lougheed, G.D. (1993) "Comparison of ASTM and ISO Full-Scale Room Fire Test Methods," Proceedings of the Second International Conference on Fire and Materials, Arlington, VA. Published for the NRC of Canada by Interscience Comm. Ltd., Sept 1993

Thomas, P., and Karlsson, B. (1991) "On the Length of Flames Under Ceilings," J. of Fire Sciences 9, p.527

Williamson, R.B., Mowrer, F.W., and Fisher, F.L. (1984) "Observations of Large Scale Turbulence in Corner-Wall Experiments," Combustion Science and Technology, 41, pp. 83-89.

Zhou, L. (1992) "Solid Fuel Flame Spread and Mass Burning in Turbulent Flow," NISTIR-GCR-92-602, National Institute of Standards and Technology, Gaithersburg, MD, 20899 


\section{NOMENCLATURE}

b width of radiating (flame) zone; essentially, w

B pyrolyzing area in the arms

d depth of the layer of hot gases

D distance of the burner beneath the ceiling

$\dot{\mathrm{E}}_{\mathrm{i}} \quad$ power impinging on area $\mathrm{A}_{1}$

F fraction of plume mass flow at the ceiling which continues as a ceiling jet

$F_{i-j}$ view factor of area $j$ from area $i$

$\mathrm{g}$ acceleration of gravity

$h_{w}$ height of ceiling (i.e., of wall)

$\mathrm{H}(\mathrm{x})$ (total) heat flux to ceiling

$\mathrm{I}(\mathrm{x})$ downward radiation flux

$\ell \quad$ flame length measured from the virtual origin, in Hinkley's experiments (see Eq.(A4))

$\ell_{\mathrm{e}}$ length of extension (i.e., of arm); see figures 9 and 14

m' mass rate of flow of fuel per unit width of corridor

m mass-loss rate; mass-flow rate

$\dot{\mathrm{m}}_{\mathrm{a}}$ mass flow in the arms

$\dot{\mathrm{m}}_{\mathrm{c}}$ (upward) mass flow in the plume, at the ceiling

p parameter in Eqs.(7) and (B9)

Q power output of flame (RHR)

r dimensionless distance; see Eq.(B2)

$u$ reciprocal of $r$; see Eq.(B18)

v upward velocity of thermal (wall) plume

$v_{c}$ upward velocity of plume at the ceiling

$w$ width of wall fire/plume

$w_{j} \quad$ width of ceiling jet; see Eq.(14)

$w_{c}$ critical width of vertical plume

$\mathrm{x}$ coordinate indicating vertical position (horizontal position, for Eqs.(A1) and (A2)

$\mathrm{x}_{\mathrm{f}}$ flame-tip height 
$\mathrm{x}_{\mathrm{o}}$ distance of a "virtual origin" behind the rear of a corridor [Eqs.(A1)-(A3)]

$\mathrm{x}_{\mathrm{p}}$ pyrolysis front height

$\mathrm{X}$ dimensionless distance; see Eq.(B2)

y coordinate for horizontal position on the wall

$\mathrm{y}_{\mathrm{e}}$ extent of pyrolysis zone in arm (see Figure 14)

Y dimensionless distance; see Eq.(B2)

$\mathrm{Y}_{\mathrm{i}}$ dimensionless thickness of hot layer

$Y_{m}$ dimensionless height of room

$\mathrm{z}$ coordinate for horizontal position orthogonal to the wall

\section{Greek symbols:}

$\delta \quad$ width of arms (extensions)

$\Delta$ thickness of ceiling jet; see Eq.(13)

$\phi_{\mathrm{r}}$ flux from ceiling flame

$\phi_{\mathrm{rm}}$ mean flux from ceiling flame

$\rho_{\mathrm{a}}$ density of the ambient air

$\rho_{\mathrm{g}}$ density of plume gas

$\rho_{\mathrm{gc}}$ density of plume gas at the ceiling

$\theta$ thickness of the plume

$\theta_{\mathrm{a}}$ thickness of arm, where it meets the wall plume

$\theta_{c}$ thickness of wall plume at the ceiling 
The most nearly relevant data here are from Hinkley et al (1984). They had a burner against an inert wall, with a "corridor" ceiling against which the flames splashed. The downward radiation flux (from hot gas/flame and hot ceiling) was found to decrease exponentially with distance from the rear of the corridor:

$$
I(x)=I_{o} \exp \left[-4.0\left(x+x_{o}\right) / l\right]
$$

where $\mathrm{x}$ is the distance measured from the rear of the corridor (in meters), $\mathrm{x}_{0}$ was the distance of a "virtual origin" behind the rear of the corridor, and $\ell$ was the flame length measured from the virtual origin. $\mathrm{I}_{\mathrm{o}}$ is the effective intensity of radiation at the virtual origin, and had the value of $500 \mathrm{~kW} / \mathrm{m}^{2}$.

The flux to the ceiling was also measured; it consisted of the convective heating flux, as well as the radiation from the hot gases/flame, and had a similar spatial dependence:

$$
H(x)=H_{o} \exp \left[-4.6\left(x+x_{o}\right) / l\right]
$$

with $\mathrm{H}_{\mathrm{o}}=700 \mathrm{~kW} / \mathrm{m}^{2}$. With their configuration, the peak flux to the ceiling was $170 \mathrm{~kW} / \mathrm{m}^{2}$. The peak downward flux was $150 \mathrm{~kW} / \mathrm{m}^{2}$; this is high enough to ignite most combustible materials within a few seconds. Hinkley et al assumed that there was a wood floor; they found that the flux was sufficiently intense that the floor would ignite and that the resulting fire would spread. They carried out the calculation for several assumed ceiling types, including an asbestos ceiling, a non-combustible, perfectly insulating ceiling, and several types of flammable ceiling. For the non-flammable as well as for several of the flammable ceilings, the results were very similar to the results that are observed for the spread of flame on a vertical wall: for wood materials, the upward spread ceases beyond a certain point; the pyrolysis front attains an asymptotic value. (For some other flammable ceilings, the downward flux is so high that spread continues and even accelerates). Whether either of these behaviors could occur for a vertical flame alone is doubtful.

The location of the virtual origin correlated very well with $\mathrm{D}$, the distance of the burner beneath the ceiling:

$$
x_{0} \approx 0.66+0.682 D+0.64 D^{2}
$$

The flame lengths $\ell$ (measured from the virtual origin) were considerably greater than the analogous flame heights. For their experiments, using "town gas," they found that

$$
l=220\left(\frac{m^{\prime}}{\rho_{a} \sqrt{g}}\right)^{2 / 3}
$$


Here $m^{\prime}$ ' is the mass rate of flow of fuel per unit width of corridor, $g$ is the acceleration of gravity, and $\rho_{\mathrm{a}}$ is the density of the ambient air. This expression is valid for $\ell / \mathrm{d}<24$, where $d$ is the depth of the layer of hot gases.

The dependence shown in Eq.(A4) is given because it turns out to be precisely the usual correlation found for wall fires, expressed in terms of mass flow rather than enthalpy flow. Moreover, the coefficient is about four times larger than in the latter case; that is, the horizontal flames were much longer than ones rising vertically from the same fuel bed. This has important implications about entrainment and combustion which will be pursued later; it suffices to emphasize them, at the moment.

The exponential decrease of the heat fluxes found in Eqs.(A1) and (A2) is interesting, in light of the fact that in the intermittent region, vertical flames have a power-law decrease in total heat flux (Mitler, 1990). Kulkarni et al (1991, 1992), however, have made an equally good fit to those fluxes with an exponential distribution, and this is completely analogous.

Again, the difference between (A1) and (A2) arises principally because the latter includes convective heat transfer. Similar exponentially-decreasing fluxes (radiative and total) can be expected for the flame extensions being considered here. 
Appendix B. View Factors and Fluxes

Consider the radiation back to the original vertical wall section, first (see $\mathrm{A}^{\prime \prime}$, figure $13 \mathrm{~b}$, and figure 15). Thus, the radiation from the flame on the ceiling to a strip running through point $\mathrm{P}$, on the wall, is wanted. The radiation flux from the flame to the wall at any height is given in the program SPREAD; it is assumed that the outward radiation is the same as that toward the wall, at every height. For $\mathrm{z}>\mathrm{h}_{\mathrm{w}}$, we now have that outward flux radiating back to the floor, the wall, and the arms (on the wall).

Consider the area $A_{2}$, of length $a$, width $b$, radiating to the narrow strip of area $\mathrm{dA}_{1}$, located at the distance $c$ (see figure 15). We have available the view factor from $\mathrm{dA}_{1}$ to $\mathrm{A}_{2}$; it is (Siegel and Howell, 1981)

$$
F_{d A_{1}-A_{2}}=\frac{1}{\pi}\left[\tan ^{-1} \frac{1}{Y}+\frac{Y}{2} \log \left(\frac{Y^{2}\left(r^{2}+1\right)}{r^{2}\left(Y^{2}+1\right)}\right)-\frac{Y}{r} \tan ^{-1} \frac{1}{r}\right]
$$

where

$$
\mathrm{X} \equiv \mathrm{a} / \mathrm{b}, \quad \mathrm{Y} \equiv \mathrm{c} / \mathrm{b}, \text { and } \mathrm{r}^{2} \equiv \mathrm{X}^{2}+\mathrm{Y}^{2} \text {. }
$$

If the outward flux from the area $\mathrm{A}_{2}$ were uniform, we would obtain the energy flux impinging on $\mathrm{dA}_{1}$ by using the view factor $\mathrm{F}_{\mathrm{A} 2-\mathrm{dA} 1}$ which is obtained from $\mathrm{F}_{\mathrm{dA} 1-\mathrm{A} 2}$ via the reciprocity relation

$$
F_{A_{2}-d A_{1}} A_{2}=F_{d A_{1}-A_{2}} d A_{1}
$$

However, the emitted radiation varies from point to point, and the power impinging on $\mathrm{dA}_{1}$ is therefore given by

$$
d \dot{E}_{1}=\int_{0}^{\infty} \phi_{r}(a) d A_{2} F_{d 2-d 1}(a)
$$

where the subscripts $d 1$ and $d 2$ are shorthand for $\mathrm{dA}_{1}$ and $\mathrm{dA}_{2}$, respectively.

We therefore first find the (differential) view factor $F_{\mathrm{d} 1-\mathrm{d} 2}$ from a strip of length $\mathrm{b}$ and width da, at a, radiating to the strip (of width $d c$ ) at $P$.

Since $\mathrm{dA}_{2}=\mathrm{b}$ da (where $\mathrm{a}=\mathrm{bX}$ ) and $\mathrm{dA}_{1}=\mathrm{b} d \mathrm{~d}$, Eq.(B1) implies that

$$
F_{d_{1}-d_{2}}=d X \frac{\partial F}{\partial X}=d X \frac{X Y \tan ^{-1}(1 / r)}{\pi r^{3}}
$$

From Eq.(B4) and the reciprocity theorem, we have 


$$
d \dot{E}_{1}=\int \phi_{r}(a) d A_{1} F_{d 1-d 2}
$$

and using equation (B5), (B6) becomes

$$
d \dot{E}_{1}=\frac{d A_{1} Y}{\pi} \int_{0}^{\infty} \phi_{r}(b X) \frac{X}{\left(X^{2}+Y^{2}\right)^{3 / 2}} \tan ^{-1}\left(X^{2}+Y^{2}\right)^{-1 / 2} d X
$$

This integral can be done exactly for the case $\phi_{\mathrm{r}}=$ const. On the other hand, we would expect that the flux falls off exponentially, as given by Eq.(18). For an exponential or a power-law fall-off, however, the integral in Eq.(28) is not analytically tractable. But if we use the meanvalue theorem to write the integral in Eq. (28) as

$$
M=\tan ^{-1}\left(\bar{X}^{2}+Y^{2}\right)^{-1 / 2} \int_{0}^{\infty} \phi_{r}(b X) \frac{X d X}{\left(X^{2}+Y^{2}\right)^{3 / 2}}
$$

then with the choice

$$
\phi_{r}(x)=\phi_{r}(0) e^{-q x}=\phi_{r}(0) e^{-q b x},
$$

for $\phi_{\mathrm{r}}$, as given by Eq.(18), an exact integration can be carried out. This results in

$$
d \dot{E}_{1}=\frac{d A_{1}}{\pi}\left[\tan ^{-1}\left(\bar{X}^{2}+Y^{2}\right)^{-1 / 2}\right] \phi_{r}(0)\left\{1+\frac{\pi}{2} \eta\left[N_{0}(\eta)-H_{0}(\eta)\right]\right\}
$$

where $N_{0}$ is the zeroth-order Neumann function (identical to $Y_{0}$, the Bessel function of the second kind), $\mathrm{H}_{0}$ is the Struve function of order zero, and

$$
\eta \equiv q b Y
$$

A calculation shows that the mean value of $\mathrm{X}$ is about $\mathrm{Y} / 2$, and that yields

$$
d \dot{E}_{1}=\frac{d A_{1}}{\pi} \tan ^{-1}\left(\frac{0.9}{Y}\right) \phi_{r}(0)\left\{1+\frac{\pi}{2} \eta\left[N_{0}(\eta)-H_{0}(\eta)\right]\right\}
$$

We can obtain a result in terms of more familiar functions with the choice

$$
\phi_{r}(x)=\phi_{r}(0) e^{-p x^{2}}=\phi_{r}(0) e^{-p b^{2} X^{2}}
$$

for $\phi_{\mathrm{r}}$ (this $\mathrm{p}$ is unrelated to the one found in Eq.(7)); that yields

$$
d \dot{E}_{1}=\frac{d A_{1}}{\pi}\left[\tan ^{-1}\left(\bar{X}^{2}+Y^{2}\right)^{-1 / 2}\right] \phi_{r}(0)\left[1-\sqrt{\pi} \xi e^{\xi^{2}} e r f c \xi\right]
$$

where 


$$
\xi \equiv \sqrt{p} b Y
$$

A simple alternative is to assume that the radiation flux from $\mathrm{A}_{2}$ has some mean value $\phi_{\mathrm{rm}}$ out to the flame-tip height and zero beyond. In that case, with the definitions

and

$$
\begin{aligned}
& a \equiv x_{f}-h_{w}, \\
& X_{o}=a / b=\left(x_{f}-h_{w}\right) / b,
\end{aligned}
$$

$$
u \equiv \frac{1}{\sqrt{Y^{2}+X_{o}^{2}}}=\frac{b}{\sqrt{c^{2}+a^{2}}}
$$

Eq.(B7) yields Eq.(B19):

$$
d \dot{E}_{1} \approx \frac{d A_{1}}{\pi} Y \phi_{r m}\left[\frac{1}{Y} \tan ^{-1}(1 / Y)-u \tan ^{-1} u+0.5 \log \left(1+u^{2}\right)+0.5 \log \left[\frac{Y^{2}}{1+Y^{2}}\right]\right]
$$

While this eliminates the need to make a judicious choice for the parameter $\mathrm{p} \mathrm{in} \mathrm{Eq.(B11),} \mathrm{it}$ requires an equally judicious choice for the mean value of $\phi_{\mathrm{r}}$, in Eq.(B19). On the other hand, this approach also permits the radiation to the arms to be readily found, as well. Note that Eq.(B19) is just Eq.(B1).

Next, we want the radiation impinging on the arms, from the ceiling flame. The power to the arms is again given by Eq.(B6), but with the appropriate view factor. The view factor from a surface element $\mathrm{dA}_{1}$ on the wall, a distance $c$ down from the ceiling, to the finite rectangle $A_{2}$ on the ceiling (see Figure 16) is

$$
F_{d 1-2}=\frac{1}{2 \pi}\left[\tan ^{-1} \frac{1}{Y}-\frac{Y}{r} \tan ^{-1} \frac{1}{r}\right]
$$

with the same definitions for $\mathrm{X}, \mathrm{Y}$, and $\mathrm{r}$ as in Eq.(B2). Then by a simple subtraction, we find that from $\mathrm{dA}_{1}$ to the shaded area $\mathrm{A}_{3}$ in figure 17 , we have

$$
F_{d 1-3}=\frac{1}{2 \pi}\left[\tan ^{-1}\left(\frac{z+b}{c}\right)-\tan ^{-1}\left(\frac{z}{c}\right)-\frac{c}{\sqrt{a^{2}+c^{2}}}\left(\tan ^{-1}\left(\frac{1}{r}\right)-\tan ^{-1}\left(\frac{1}{r_{1}}\right)\right]\right]
$$

where

$$
r=\frac{\sqrt{a^{2}+c^{2}}}{z+b}
$$


and

$$
r_{1}=\frac{\sqrt{a^{2}+c^{2}}}{z}
$$

Note that we can non-dimensionalize $\mathrm{z}$ to $\mathrm{Z}$ by dividing $\mathrm{z}$ by $\mathrm{b}$, as was done for $\mathrm{X}$ and $\mathrm{Y}$; this is not necessary here, however. If we again assume a uniform flux to be emitted from $A_{3}$, then the energy falling on the area $\mathrm{dA}_{1}$ on the arm is

$$
d \dot{E}_{1}=\phi_{r m} d A_{1} F_{d 1-3}
$$

where we have again used the reciprocity theorem.

Thus, we can get the needed fluxes to the wall and to the arms from Eqs.(B19) and (B24), respectively. At present, however, SPREAD assumes a uniform external flux on the section of wall within (i.e., contiguous to) the hot layer and another to the layer below ("upper" and "lower wall", respectively). Therefore Eq.(B19) must be integrated between $\mathrm{z}=\mathrm{z}_{\mathrm{i}}$ (the interface height) and $z=h_{w}$ (the ceiling height), and Eq.(B24) between $h_{w}-\delta$ and $h_{w}$.

Integration of Eq.(B19) over Y is tedious but straightforward, and yields

$$
\dot{E}_{1} \approx \frac{\phi_{r m} b^{2}}{\pi}\left[A-B+C-D+\frac{E-F-G+H}{4}\right]
$$

where

$$
\begin{gathered}
A \equiv \frac{\tan ^{-1} x_{m}}{x_{m}}+0.5 \ln \left(1+x_{m}^{2}\right)-\ln x_{m} \\
B \equiv \frac{\tan ^{-1} x_{i}}{x_{i}}+0.5 \ln \left(1+x_{i}^{2}\right)-\ln x_{i} \\
C \equiv \frac{\tan ^{-1} u_{i}}{u_{i}}+0.5 \ln \left(1+u_{i}^{2}\right)-\ln u_{i} \\
D \equiv \frac{\tan ^{-1} u_{m}}{u_{m}}+0.5 \ln \left(1+u_{m}^{2}\right)-\ln u_{m} \\
E \equiv\left(1+X^{2}+Y_{m}^{2}\right) \ln \left(1+X^{2}+Y_{m}^{2}\right)-\left(X^{2}+Y_{m}^{2}\right) \ln \left(X^{2}+Y_{m}^{2}\right) \\
F \equiv\left(1+X^{2}+Y_{i}^{2}\right) \ln \left(1+X^{2}+Y_{i}^{2}\right)-\left(X^{2}+Y_{i}^{2}\right) \ln \left(X^{2}+Y_{i}^{2}\right)
\end{gathered}
$$




$$
H \equiv\left(1+Y_{i}^{2}\right) \ln \left(1+Y_{i}^{2}\right)-Y_{i}^{2} \ln Y_{i}^{2}
$$

and

$$
G \equiv\left(1+Y_{m}^{2}\right) \ln \left(1+Y_{m}^{2}\right)-Y_{m}^{2} \ln Y_{m}^{2}
$$

with

$$
\begin{gathered}
Y_{i} \equiv z_{i} / b, \quad Y_{m} \equiv h_{w} / b \\
x_{m} \equiv 1 / Y_{m}, \quad x_{i} \equiv 1 / Y_{i}, \\
u_{i} \equiv \frac{1}{\sqrt{X^{2}+Y_{i}^{2}}}, \quad \text { and } \quad u_{m} \equiv \frac{1}{\sqrt{X^{2}+Y_{m}^{2}}} .
\end{gathered}
$$

We can again simplify this very considerably by taking an average value for $\mathrm{Y}$ in Eq.(B19). Thus, starting again from Eq.(B19) we find, for the lower wall,

$$
\dot{E}_{1} \approx \frac{\phi_{r m} b^{2}}{\pi}\left(Y_{m}-Y_{i}\right)\left[\tan ^{-1} \frac{1}{Y}-\frac{\bar{Y}}{\bar{r}} \tan ^{-1} \frac{1}{\bar{r}}+\frac{\bar{Y}}{2} \ln \left\{\frac{\left(1+\bar{r}^{2}\right) \bar{Y}^{2}}{\bar{r}^{2}\left(1+\bar{Y}^{2}\right)}\right\}\right]
$$

where

$$
Y_{i}=\left(h_{w}-z_{i}\right) / b
$$

corresponds to the normalized thickness of the hot layer, and

$$
\mathrm{Y}_{\mathrm{m}}=\mathrm{h}_{\mathrm{w}} / \mathrm{b}
$$

corresponds to the room height. Also,

$$
\bar{r} \approx \sqrt{X^{2}+\bar{Y}^{2}}
$$

For the mean value, we may choose

$$
\bar{Y} \approx\left(Y_{i}+Y_{m}\right) / 2
$$

For the upper wall, we readily find

$$
\dot{E}_{1} \approx \frac{\phi_{r m} b^{2}}{\pi} Y_{i}\left[\tan ^{-1} \frac{1}{Y^{\prime}}-\frac{Y^{\prime}}{r^{\prime}} \tan ^{-1} \frac{1}{r^{\prime}}+\frac{Y^{\prime}}{2} \ln \left\{\frac{\left(1+r^{\prime 2}\right) Y^{\prime 2}}{r^{\prime 2}\left(1+Y^{\prime 2}\right)}\right\}\right]
$$

where

and

$$
\mathrm{Y}^{\prime} \simeq \mathrm{Y}_{\mathrm{i}} / 2
$$




$$
r^{\prime} \equiv \sqrt{X^{2}+Y^{\prime 2}}
$$

We next turn to Eq.(B24). We again let $\mathrm{dA}_{1}$ represent the entire area of interest. Thus for the pyrolyzing area $\mathrm{B}$ (see figures 13 and 14), $\mathrm{dA}_{1}$ becomes

$$
\mathrm{B}=\left(\mathrm{y}_{\mathrm{e}}-\mathrm{w} / 2\right) \delta,
$$

while for the preheating region $\mathrm{B}^{\prime}, \mathrm{dA}_{1}$ becomes

$$
\mathrm{B}^{\prime}=\left(\ell_{\mathrm{e}}-\mathrm{y}_{\mathrm{e}}+\mathrm{w} / 2\right) \delta .
$$

Moreover, choosing the midpoints of these regions to be representative, we get

$$
c=\delta / 2 \quad \text { and } \quad z=\left[y_{e}-w / 2\right] / 2
$$

so that Eq.(B6) yields

$$
\dot{E}_{1} \approx \phi_{r m}\left(y_{e}-w / 2\right) F_{d 1-3} \delta
$$

with $\mathrm{F}_{\mathrm{d} 1-3}$ given by Eq.(B21), with $\mathrm{c}$ and $\mathrm{z}$ given by Eq.(B35).

The simplest approximation to $\phi_{\mathrm{rm}}$ is found by taking

$$
\int_{0}^{\infty} \phi_{r}(x) d x=\left(x_{f}-h_{w}\right) \phi_{r m}
$$

Suppose the radiation flux is given by an equation such as (A1); that is, by Eq.(B9), where $\phi_{\mathrm{r}}(0)$ is the downward radiation flux from the flame at the intersection of the wall and ceiling. Then the integral on the left-hand side of Eq.(B37) is trivial, and we find that

$$
\phi_{r m} \approx \frac{\phi_{r}(0)}{\left(x_{f}-h_{w}\right) q}
$$


Appendix C. The program SPREAD

The following is a brief description of SPREAD: For a given igniter against a flat wall, and given the appropriate thermophysical parameters of the wall material, SPREAD calculates the time to ignition of the wall, the location and extent of the initial pyrolyzing area, the mass-loss rate, the rates of upward and lateral spread of the fire, and the resulting rate of heat release.

The input includes the experimental rate of heat release from the Cone Calorimeter (this is proportional to the mass-loss rate). Thus, the calculation automatically takes charring and transient pyrolysis into account. The input also includes the external flux impinging on the wall as a function of time and position, which the program then takes into account in making the above calculations (the present program allows for just two external fluxes: the mean external flux impinging on the part of the wall contiguous to the upper layer, and that wetting the lower layer. Generalization to more than two fluxes is straightforward).

For the lateral-spread calculation, the program takes into account the fact that the upper part of the wall has a different temperature than the lower part, so that the lateral-spread rate is greater in the upper region. Thus, the effect of having two layers is explicitly taken into account.

The power output of the igniter is user-specified, and can be an (almost) arbitrary function of time. Among the things the program does not yet have in it is the effects the presence of the ceiling has on the burning and spread rates (except insofar as the ceiling traps the upper gas layer).

The performance of SPREAD (before the changes indicated in this paper were added) for three examples is illustrated in figures 19 to 21 . Figure 19 shows the position of the pyrolysis front for a PMMA slab ignited at the bottom, as a function of time. The squares show the measured positions of the front, the solid curve the value calculated by SPREAD, the BFRL model which is being prepared for insertion into HAZARD. Figure 20 does the same for a slab of wood. Figure 21a shows the measured values of pyrolysis front and flame-tip height for a large slab of plywood preheated for $20 \mathrm{~min}$. by a $5 \mathrm{~kW} / \mathrm{m}^{2}$ radiation source, then ignited at the bottom. Figure $21 \mathrm{~b}$ shows the corresponding calculated values.

The documentation of SPREAD is given in much more detail in Mitler and Steckler (1994). Finally, the results of implementing the algorithm are shown in Fig.22: this shows the results of burning a 0.3 m-wide PMMA slab of 2.43 ( $8^{\prime}$ ) height in the open, vs. that in an enclosure. The rate of heat release is shown. Only the splashing effect and the spread of the horizontal extensions under the ceiling are included -- the effect of the extra flux from the hot layer is not shown. It was assumed that the mean flux from the flame under the ceiling is $5 \mathrm{~kW} / \mathrm{m}^{2}$. 


\section{FIGURE CAPTIONS}

Figure 1. Schematic showing how the hot layer trapped under the ceiling (as well as the ceiling itself) provides an additional external flux which increases the mass-loss rate in the pyrolyzing region and increases the heating rate (and therefore the spread rate) in the preheating region.

Figure 2. Schematic for what one might imagine is the appearance of a wall flame so high that it "splashes" on the ceiling. The figure is shown as if the ceiling were hinged where it meets the wall, and rotated back so as to lie in the same plane as the wall. All analogous figures shown hereafter use the same device.

Figure 3. Schematic of what is actually observed (see figure 5). The dotted curve indicates the possible shape of the part of the flame which lies against the ceiling; the actual shape is actually unknown: it is generally hidden by smoke.

Figure 4. Schematic showing how flame extensions in the direction of the ceiling jet produce enhanced radiation feedback to the wall.

Figure 5. Geometry assumed by Cleary and Quintiere, analogous to figure 3. The shapes on the ceiling are semicircles. Several are shown, to indicate the spread of the fire.

Figure 6. Photograph of a wall fire with the flame impinging on the ceiling. From an experiment carried out at CFR/NBS by B. Lee in 1986. Photo courtesy of R. Peacock.

Figure 7. Schematic of an intermediate-width fire, indicating the gas flows (dashed lines), the flame extensions, and some of the relevant dimensions.

Figure 8. Calculated RHR from a slab of PMMA ignited at the bottom, as a function of time. Curve NC corresponds to burning in the open. curve $C$ shows the result of subjecting the slab to the extra heating flux from the hot gases trapped in an ASTM room. The arrows at the top indicate the moments at which the pyrolysis front reaches the top of the slab, in the two cases.

Figure 9. See caption for Fig.8. The flame tips are computed to reach the ceiling at $\mathrm{t}=$ $422 \mathrm{~s}$. The dashed curve indicates schematically what the further development of the RHR might look like, with the flames shooting out along the arms. The growth rate would be still more rapid if the ceiling were flammable.

Figure 10. For a very wide fire, the ceiling flow is nearly two-dimensional.

Figure 11. Schematic for a narrow wall fire: flow occurs principally along the arms. The central jet, if there is one, may proceed as a "tendril" of gas, or fan out radially, as shown by the dashed curves.

Figure 12. The dependence of the ceiling-jet fraction $F$, as a function of the wall-fire width. Curve A: for $A<1 /(2 p)$ in Eq.(8)

Curve B: for $A=1 /(2 p)$

Curve $C$ : when there exists a critical width, $\mathrm{w}_{\mathrm{c}}$ 
Figure 13. The width $\delta$ of the arms as a function of the width $w$ of the wall fire, according to Eq.(1) (dashed curves) and Eq.(11) (solid curve).

Curve A: $2 \mathrm{Ap}<1$

Curve B: $2 A p>1$

Figure 14a. Schematic, similar to figure 7. C and C' are the luminous (flame) regions within the central jet. $C$ is the pyrolyzing region, when the ceiling is flammable (it has zero area when the ceiling is inert). B and B' are the analogous regions in the arms.

Figure 14b. A and $A^{\prime}$ are the zones for the virtual wall fire which are used to model the actual fire; that is, from which we can infer the fire strength and spread rate for configuration (a). $A^{\prime \prime}$ is the actual pyrolyzing area on the wall. The shaded areas are explained in the text (Section 5.2).

Figure 15. This figure combines figures 7 and $14 a$, and shows a few more relevant dimensions.

Figure 16. Schematic showing the geometry for the calculation of the view factor at point $\mathrm{P}$ and for the strip running through $\mathrm{P}$, from the luminous area $\mathrm{A}_{2}$.

Figure 17. Configuration similar to that shown in figure 16, but applying to the differential element $d A_{1}$ at the edge of region $A_{2}$, rather than the entire strip.

Figure 18. Applying the view factors found from figure 17 twice, we find the view factor for a point on the wall under the arm, located a distance $z$ "downstream" from $\mathrm{A}_{2}$ and a distance $\mathrm{c}$ down from the ceiling.

Figure 19. Position of the upper pyrolysis front as a function of time, for thermally-thick PMMA, NIST experiment. The difference between peak and average values arises because the pyrolysis front is not horizontal (three-dimensional burning). The solid curve is the calculation.

Figure 20. Position of the upper pyrolysis front as a function of time, for particle board. Same remarks as for Figure 19.

Figure 21a. Summary of experiment \#17 (particle board, $\phi_{\text {ext }} \approx 5 \mathrm{~kW} / \mathrm{m}^{2}$ ).

Figure 21b. Calculated values of pyrolysis front height (solid curve) and of flame-tip heights (dotted curve).

Figure 22. Rate of heat release (in $\mathrm{kW}$ ) of a PMMA slab as a function of time, with and without a ceiling. 


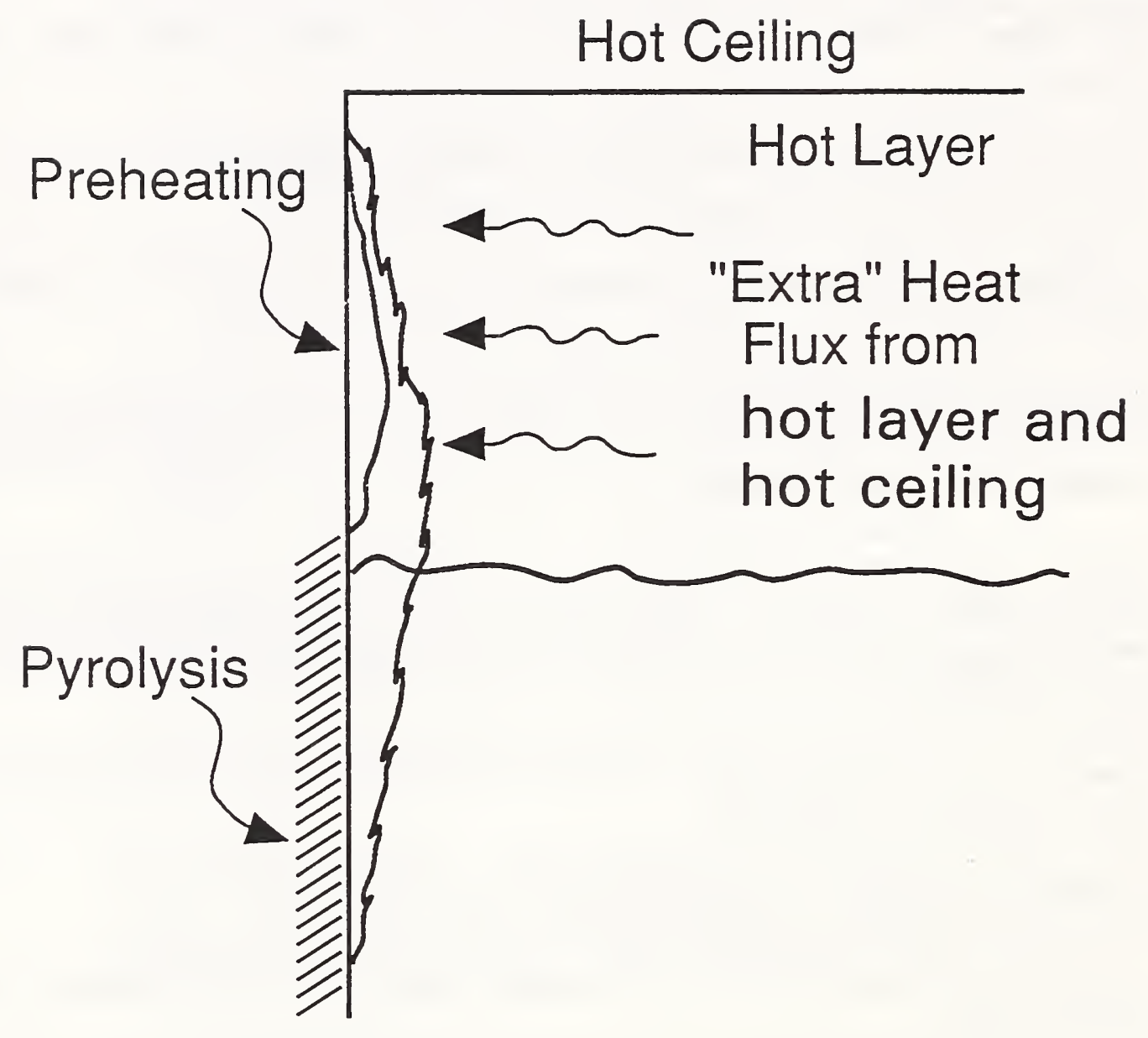

Figure 1. Schematic showing how the hot layer trapped under the ceiling (as well as the ceiling itself) provides an additional external flux which increases the mass-loss rate in the pyrolyzing region and increases the heating rate (and therefore the spread rate) in the preheating region. 


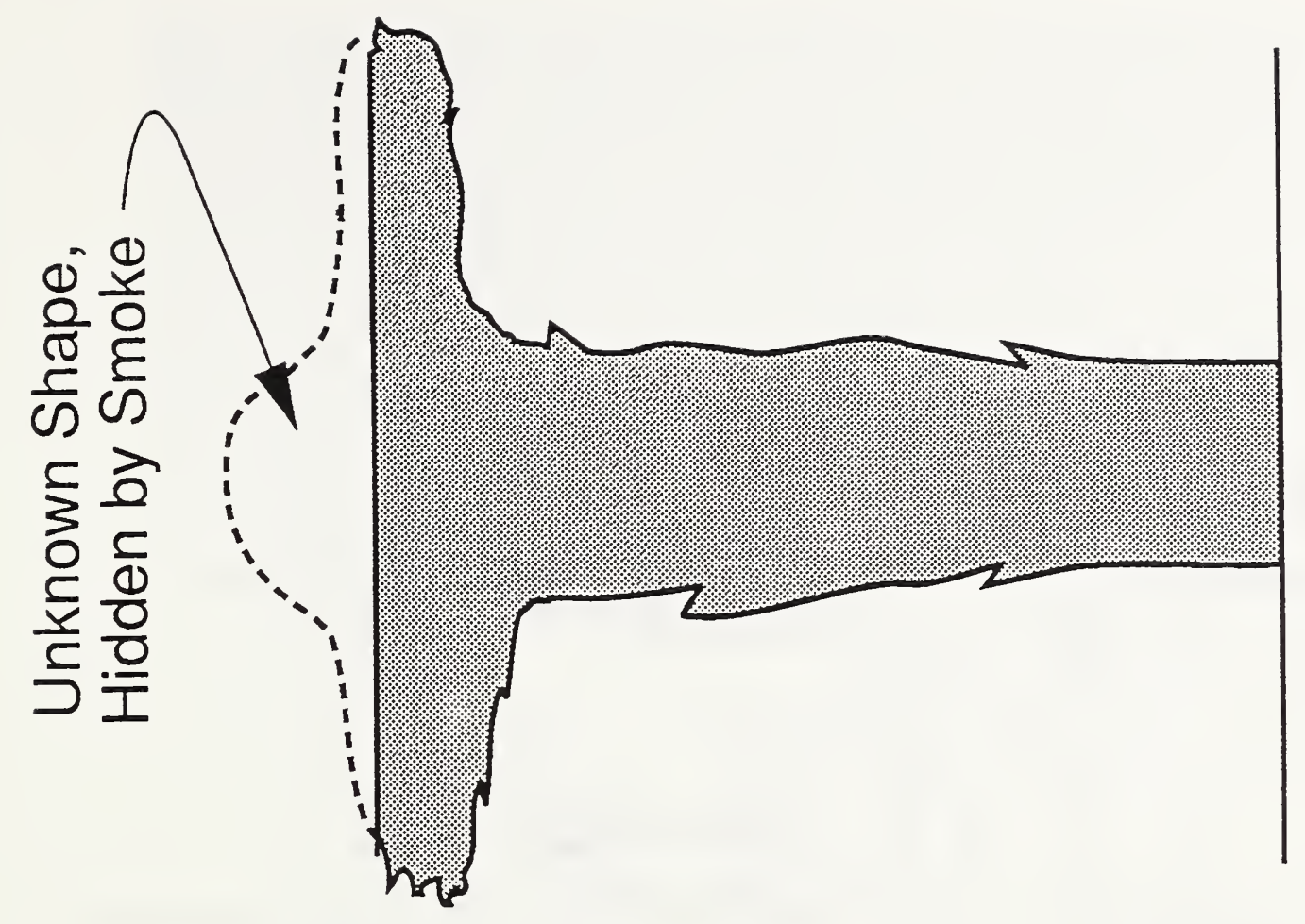

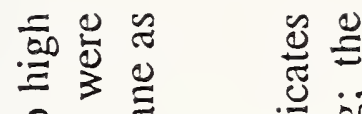

\& 00 完

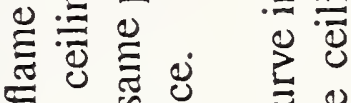

ฮ

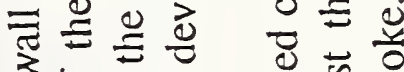

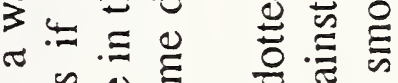

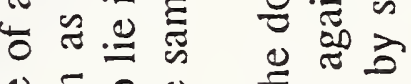

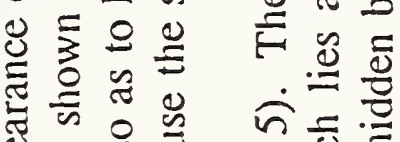

๘

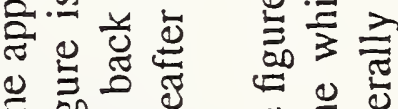

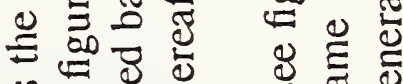

$\approx$ 可近豆

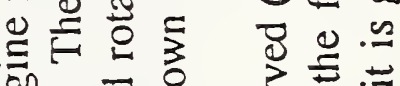

留

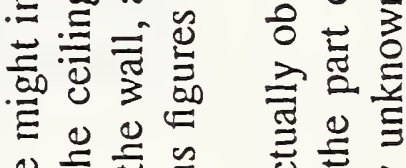

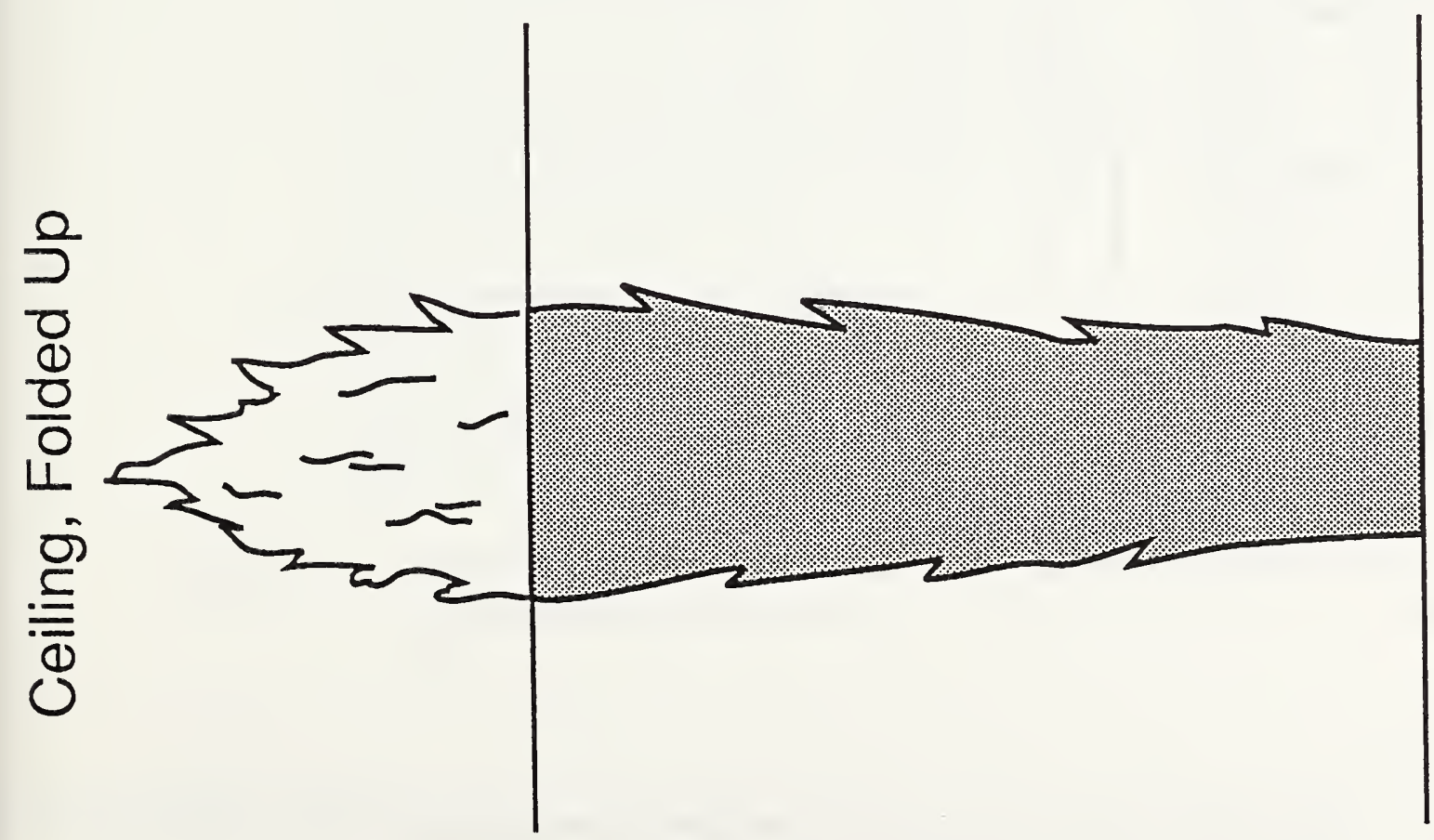

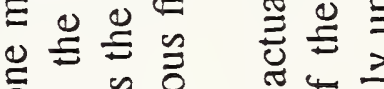

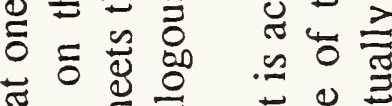

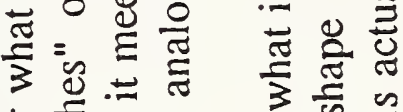

ธั

.

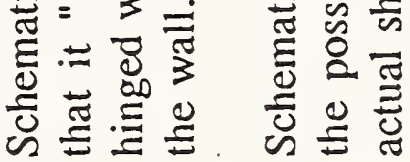

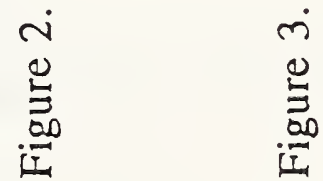




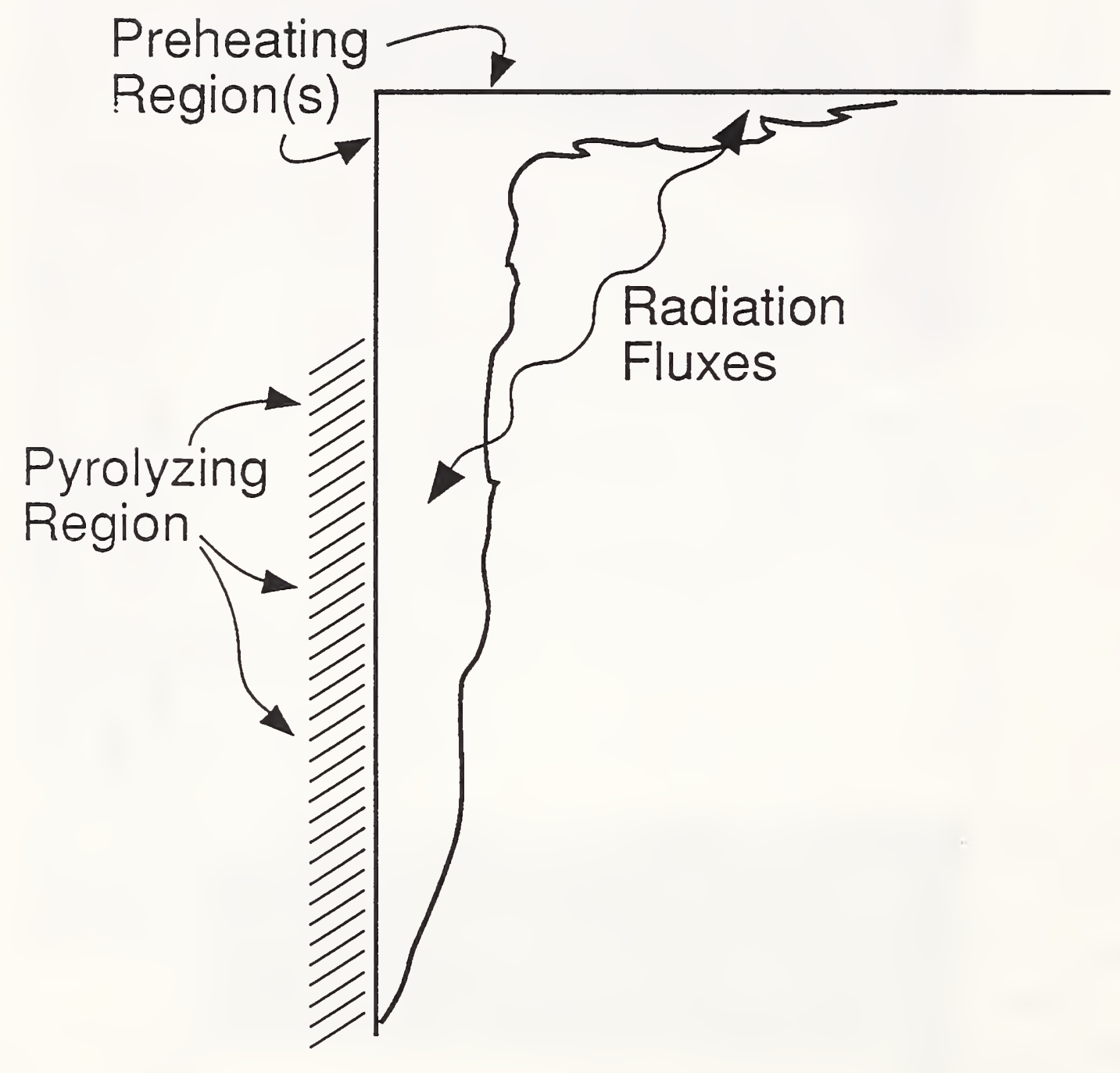

Figure 4. Schematic showing how flame extensions in the direction of the ceiling jet produc enhanced radiation feedback to the wall. 


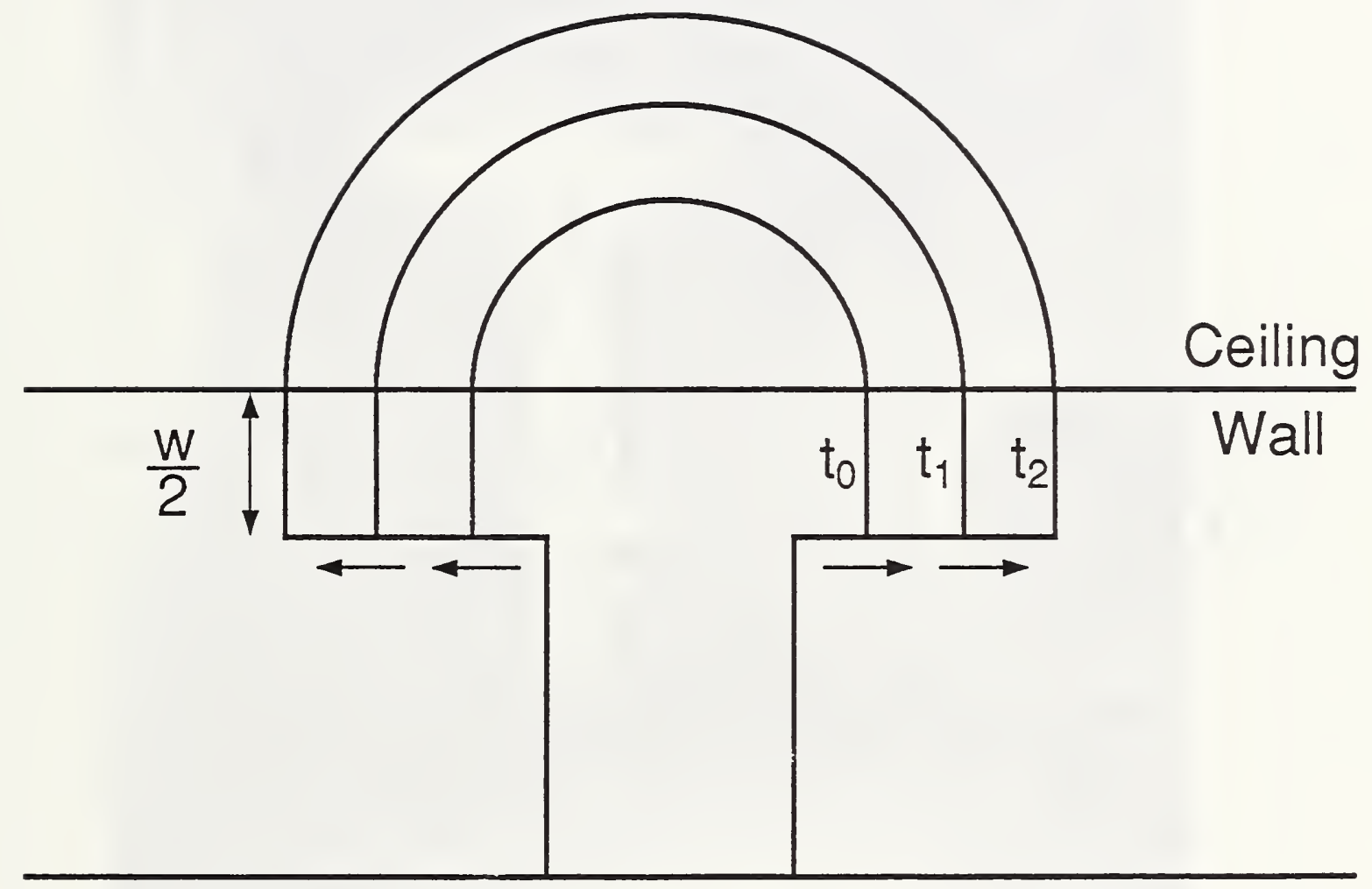

Figure 5. Geometry assumed by Cleary and Quintiere, analogous to figure 3. The shapes on the ceiling are semicircles. Several are shown, to indicate the spread of the fire. 


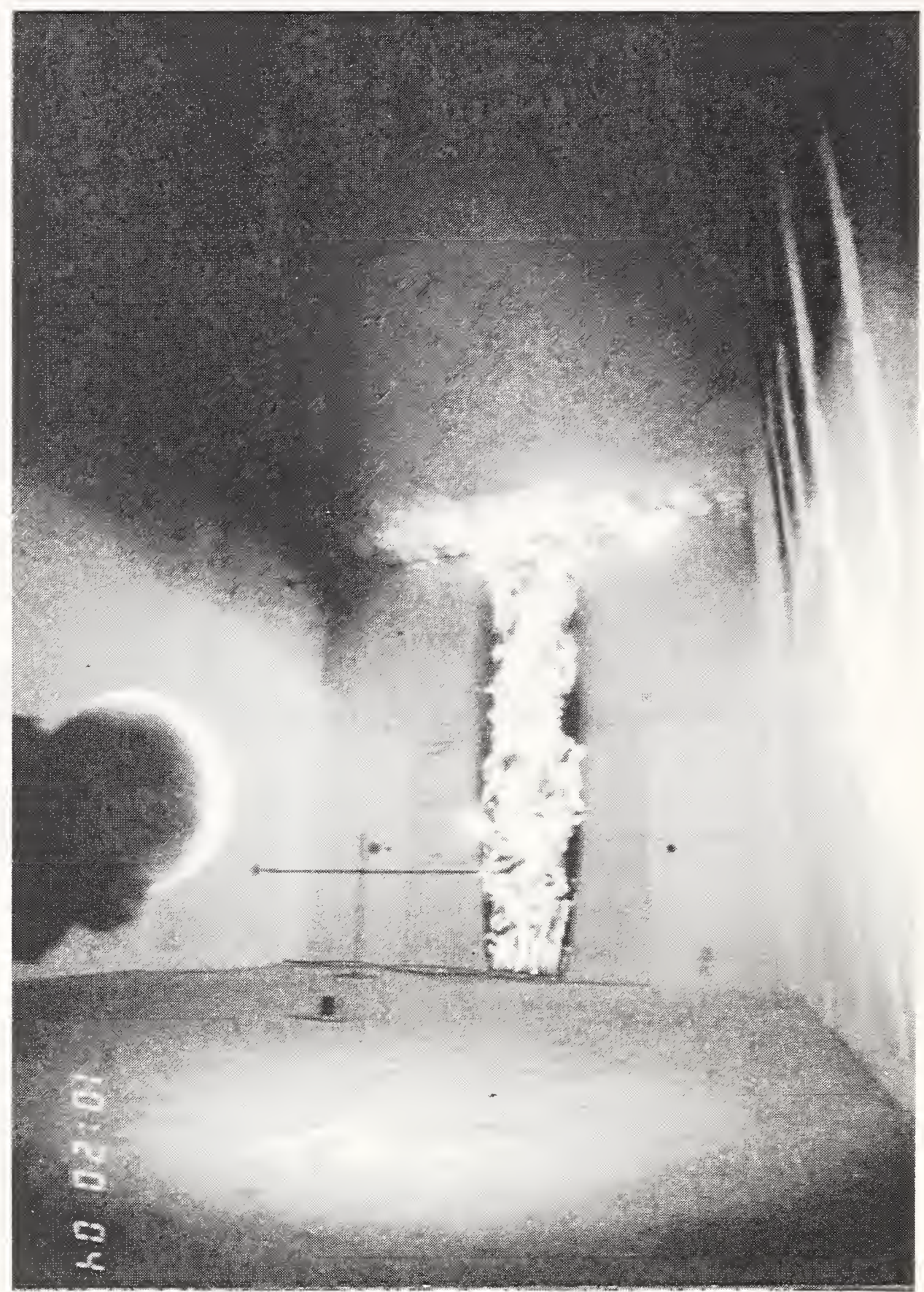

Figure 6. Photograph of a wall fire with the flame impinging on the ceiling. From an experiment carried out at CFR/NBS by B. Lee in 1986. Photo courtesy of R. Peacock. 


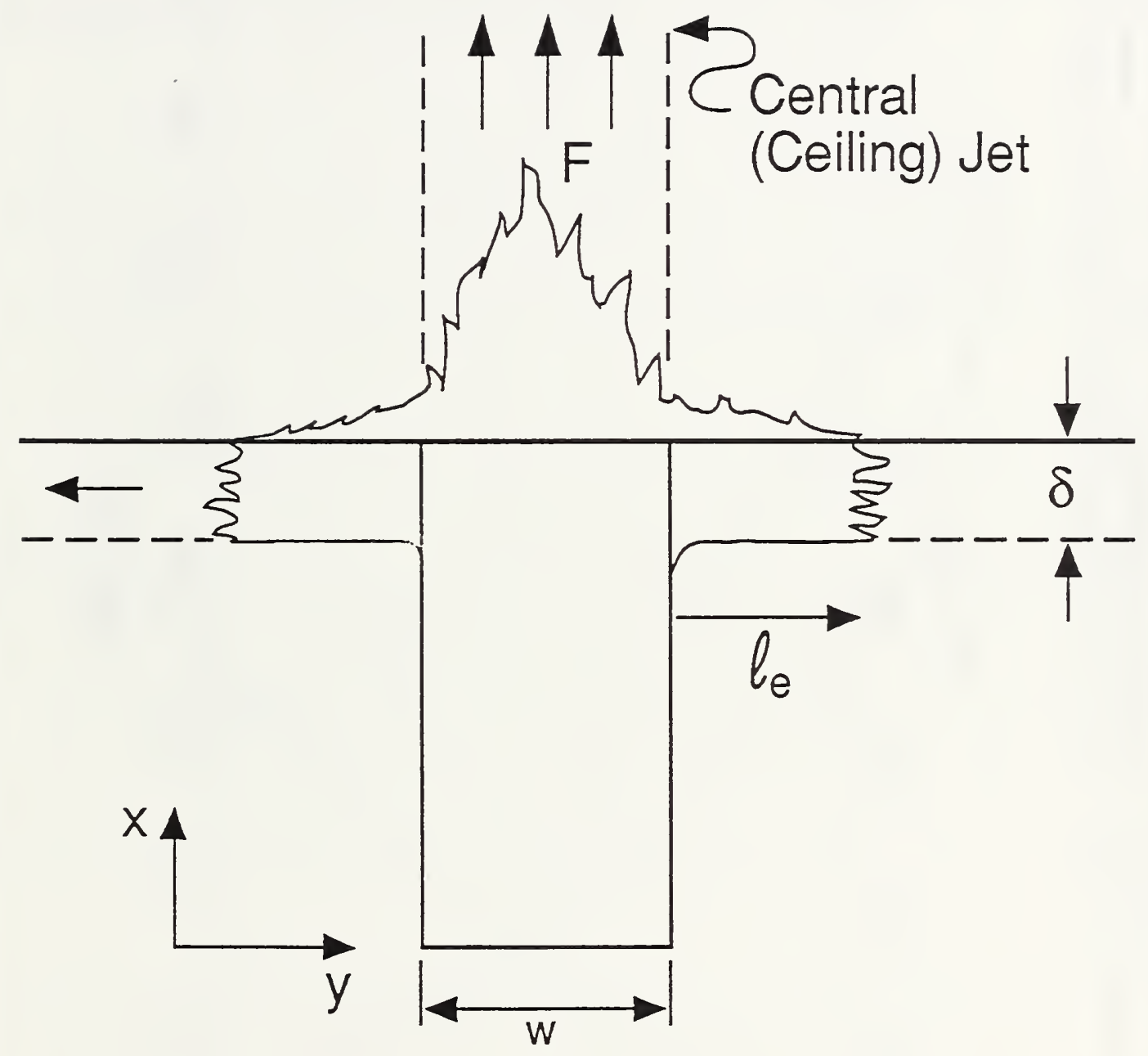

Figure 7. Schematic of an intermediate-width fire, indicating the gas flows (dashed lines), the flame extensions, and some of the relevant dimensions. 


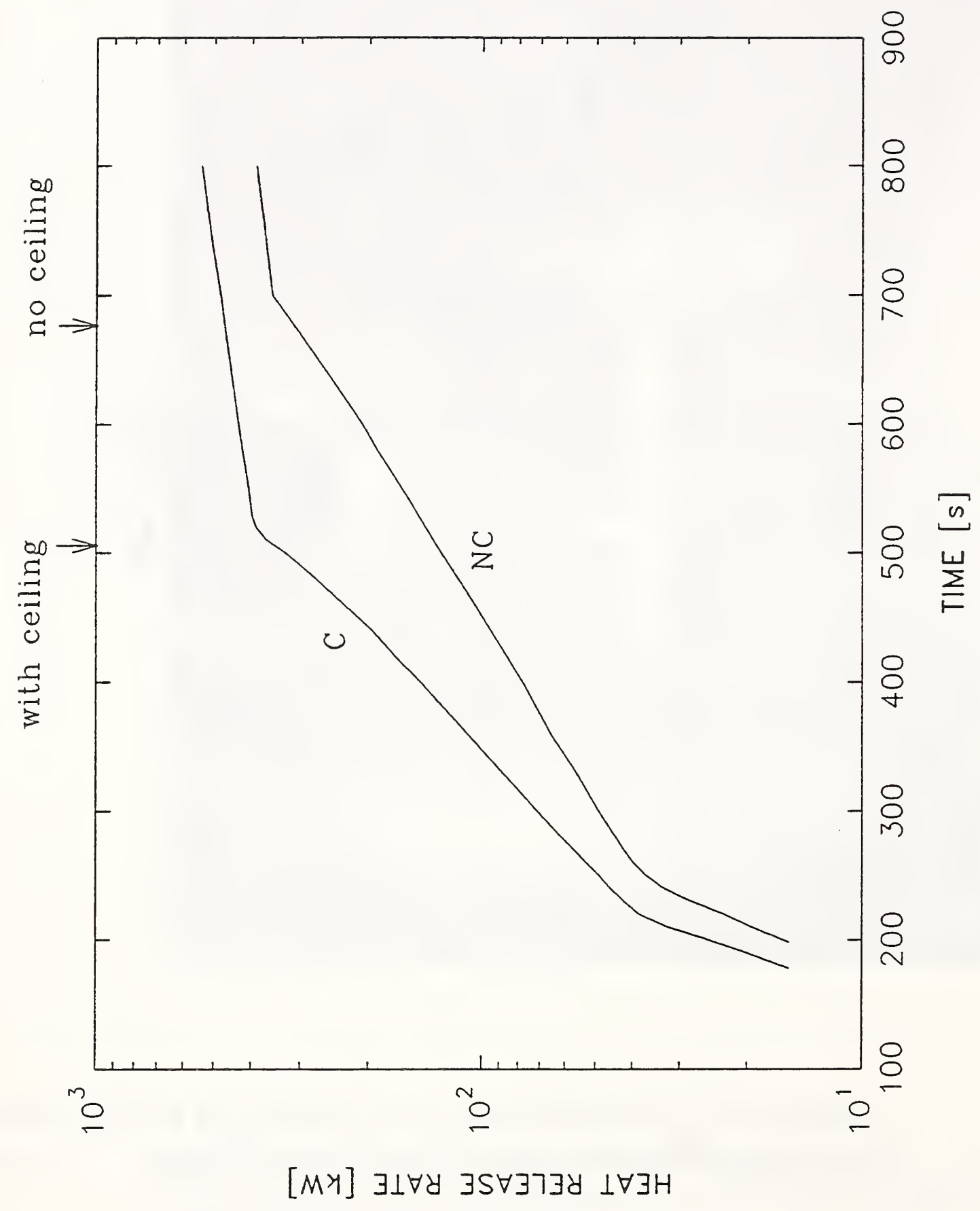

颔

훈.

可莒

记氙导

的造.

हบ 品

롱호

0. 氙

过

흥흥

Ðِّ

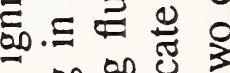

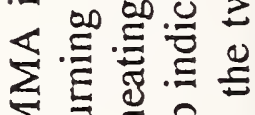

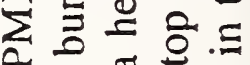

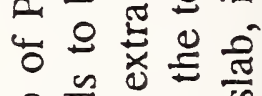

记

的

๙ क्षे

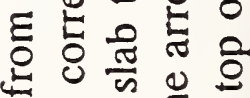

足记导导

«

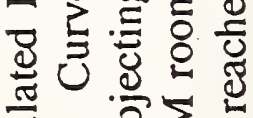

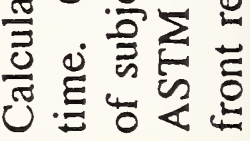

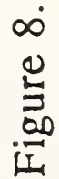




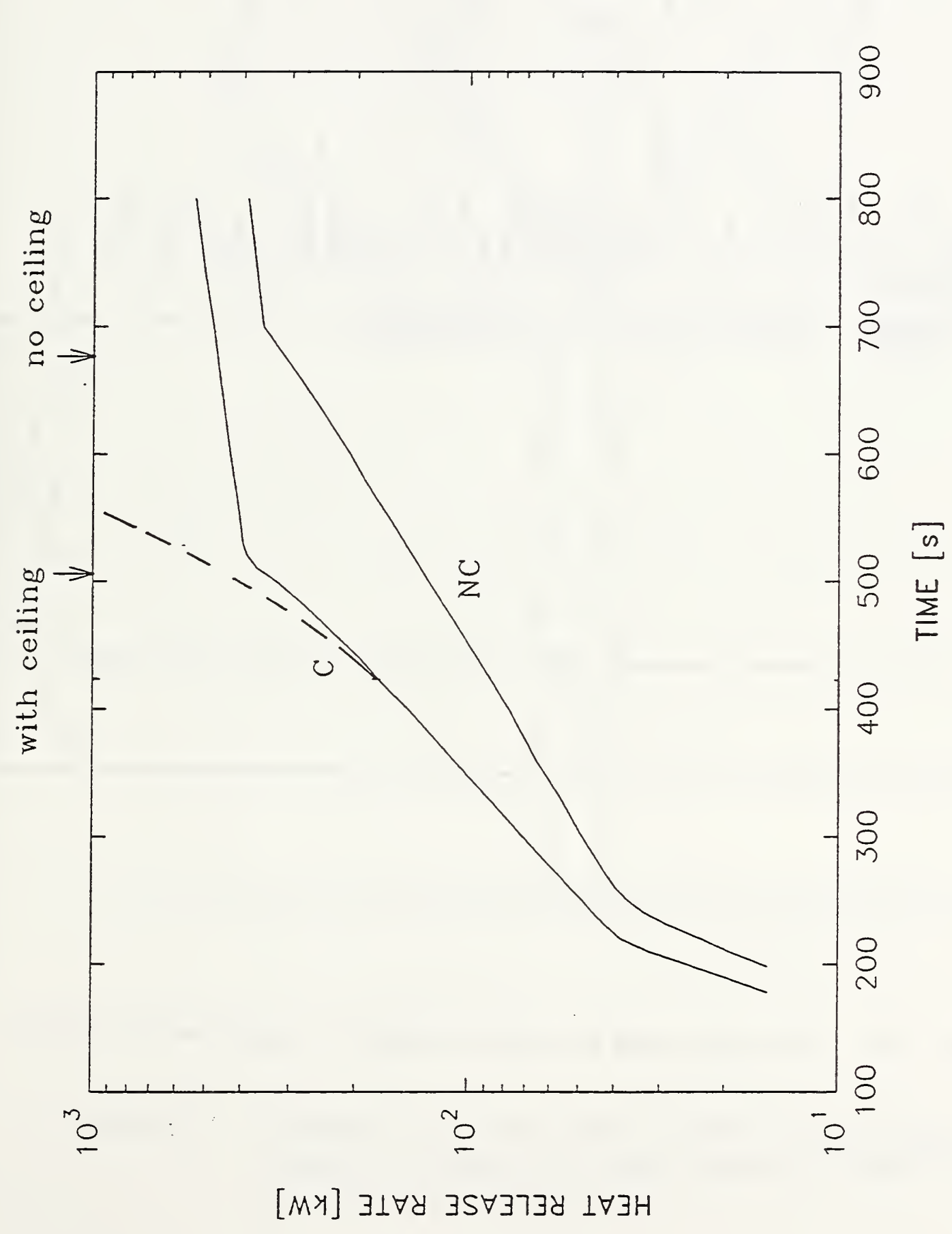

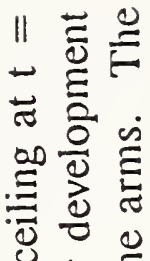

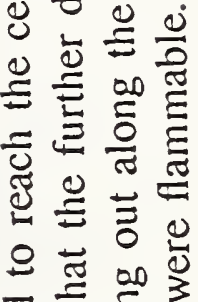

రृ

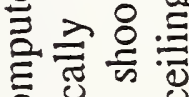

है. कू

U

๘

. ¿

岕

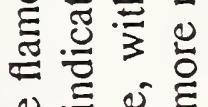

$\stackrel{\Xi}{\underline{y} \Xi}$

E范三

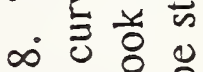

$\infty$ 용

运 䎡

능 छ

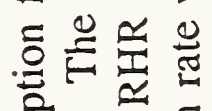

苍 i 五

ช ํ

[My] $\exists \perp \forall y \quad \exists S \forall \exists\urcorner \exists y \perp \forall \exists H$

a 


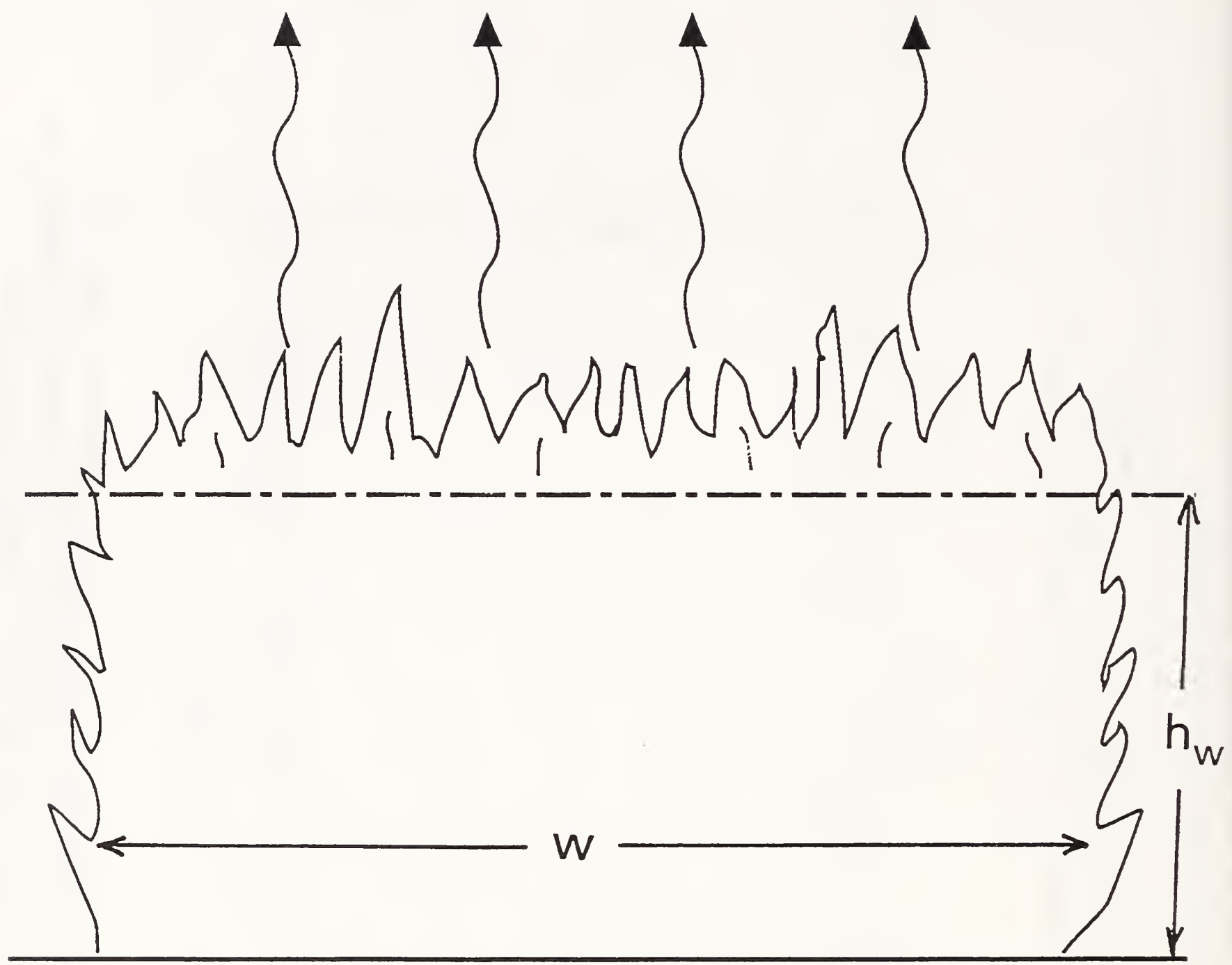

Figure 10. For a very wide fire, the ceiling flow is nearly two-dimensional. 


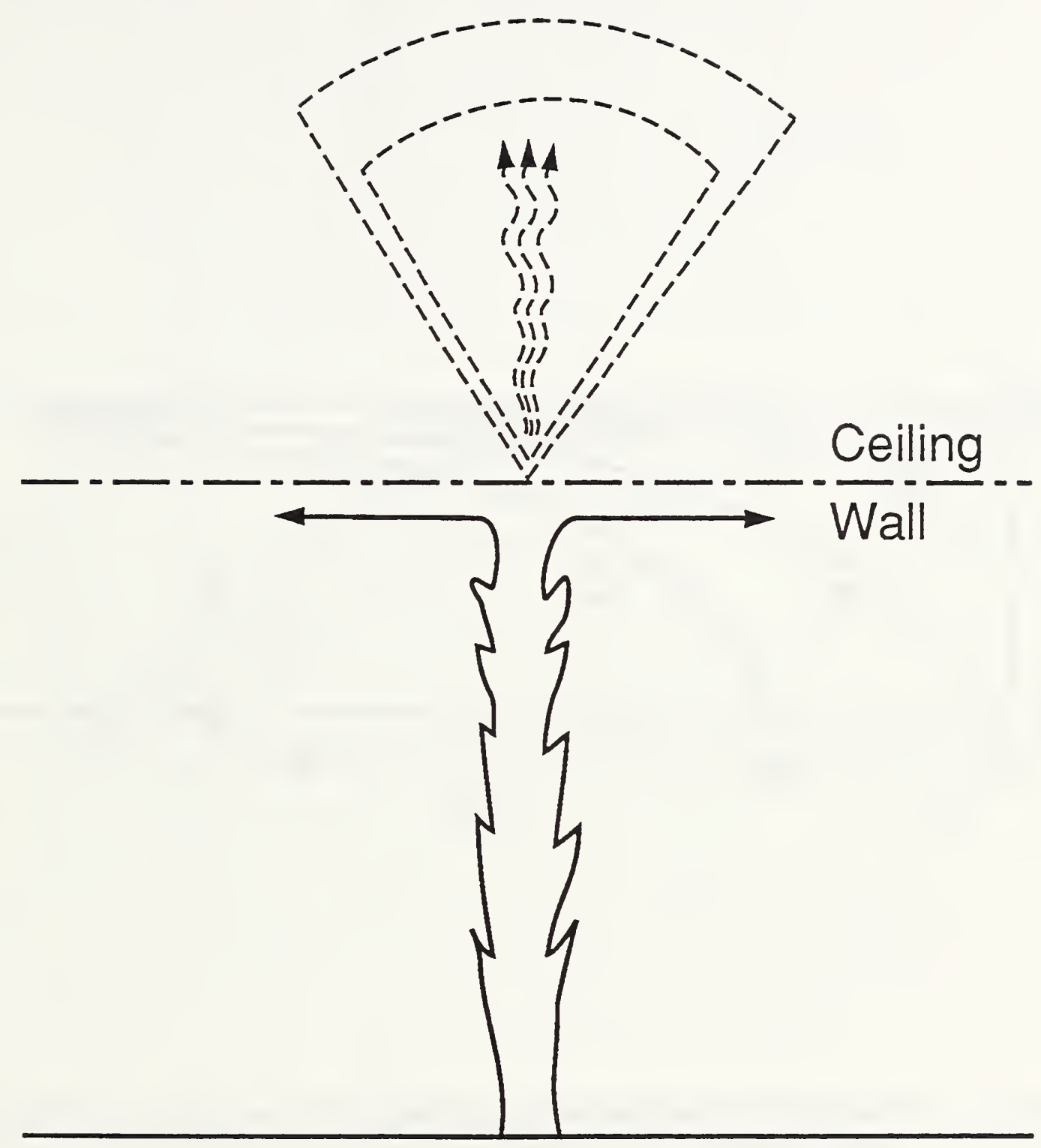

Figure 11. Schematic for a narrow wall fire: flow occurs principally along the arms. The central jet, if there is one, may proceed as a "tendril" of gas, or fan out radially, as shown by the dashed curves. 


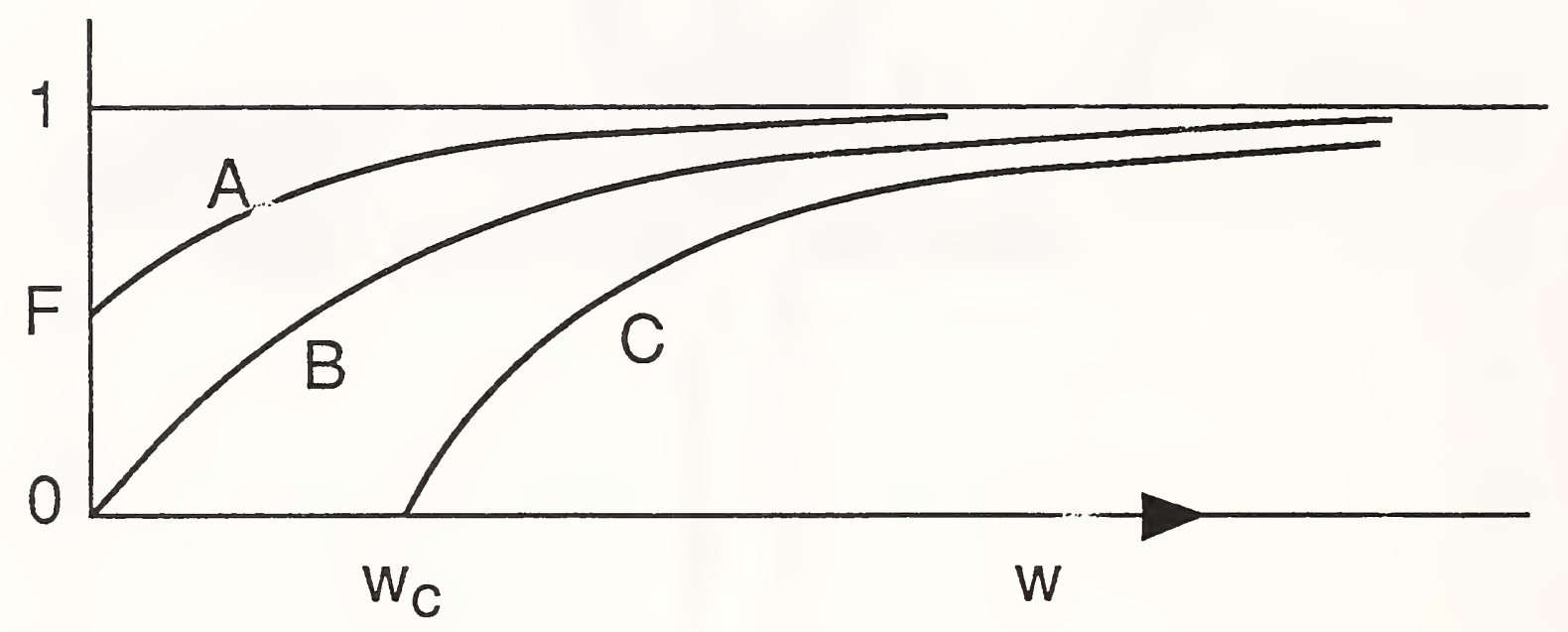

Figure 12. The dependence of the ceiling-jet fraction $F$, as a function of the wall-fire width. Curve $A$ : for $A<1 /(2 p)$ in Eq. (8)

Curve $B$ : for $A=1 /(2 p)$

Curve $C$ : when there exists a critical width, $w_{c}$ 


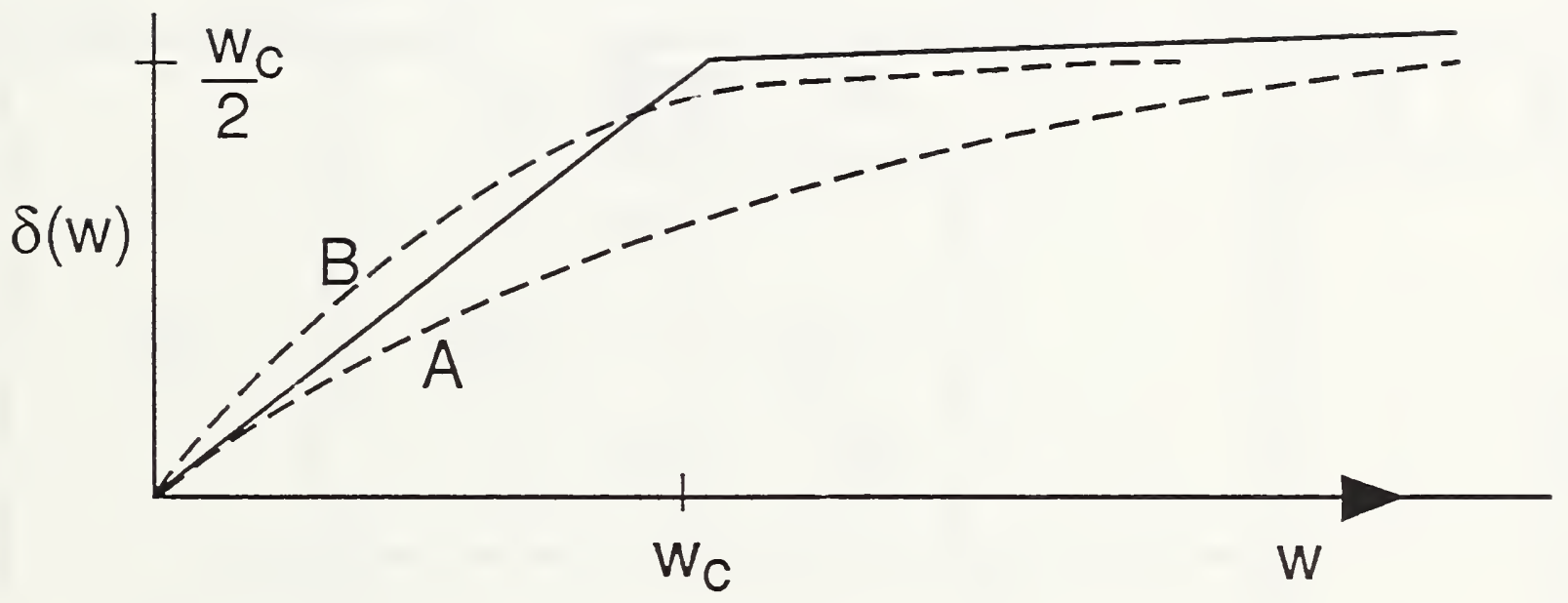

Figure 13. The width $\delta$ of the arms as a function of the width $w$ of the wall fire, according to Eq.(1) (dashed curves) and Eq.(11) (solid curve).

Curve A: 2 Ap $<1$

Curve B: $2 A P>1$ 


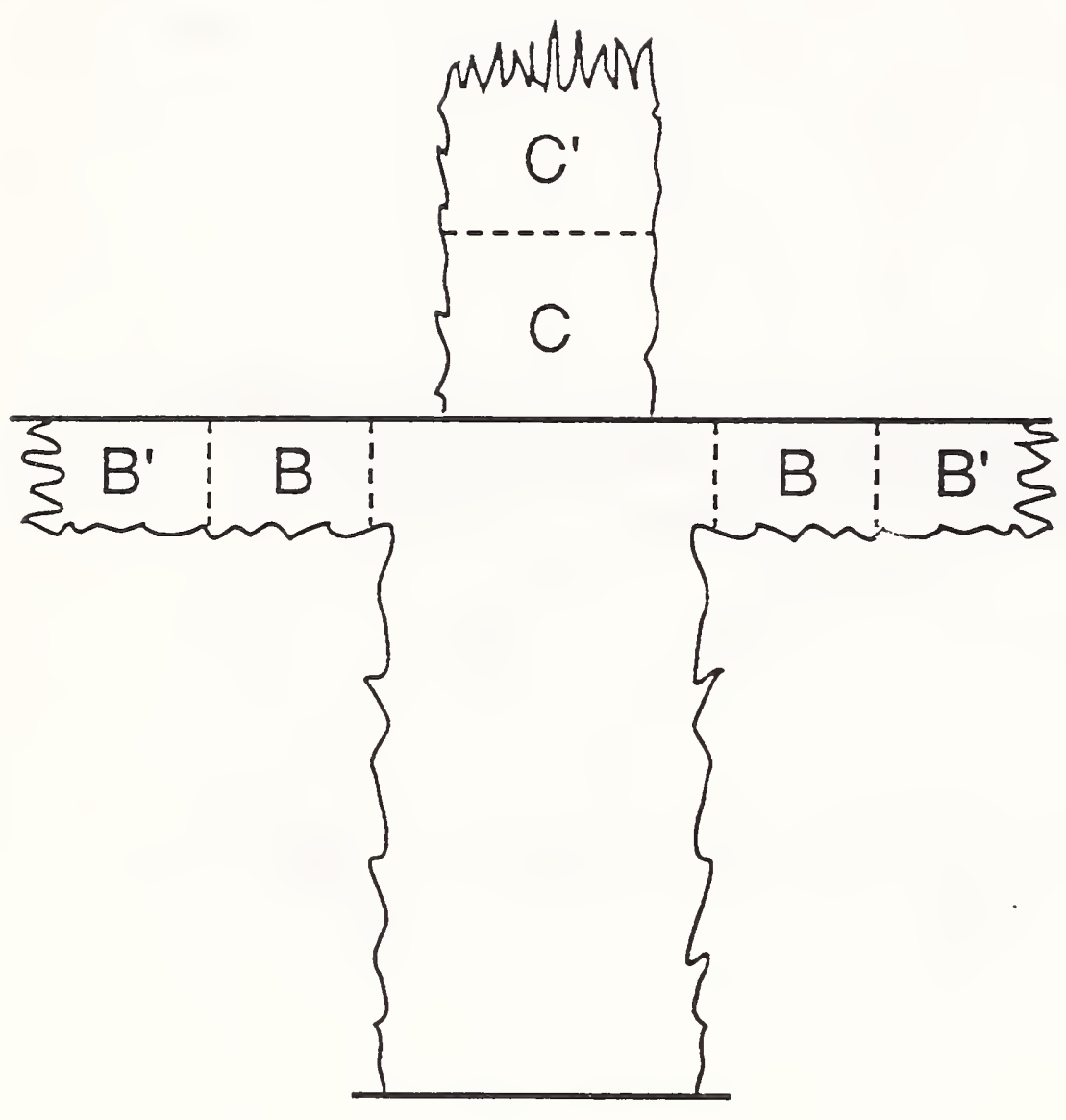

(a)

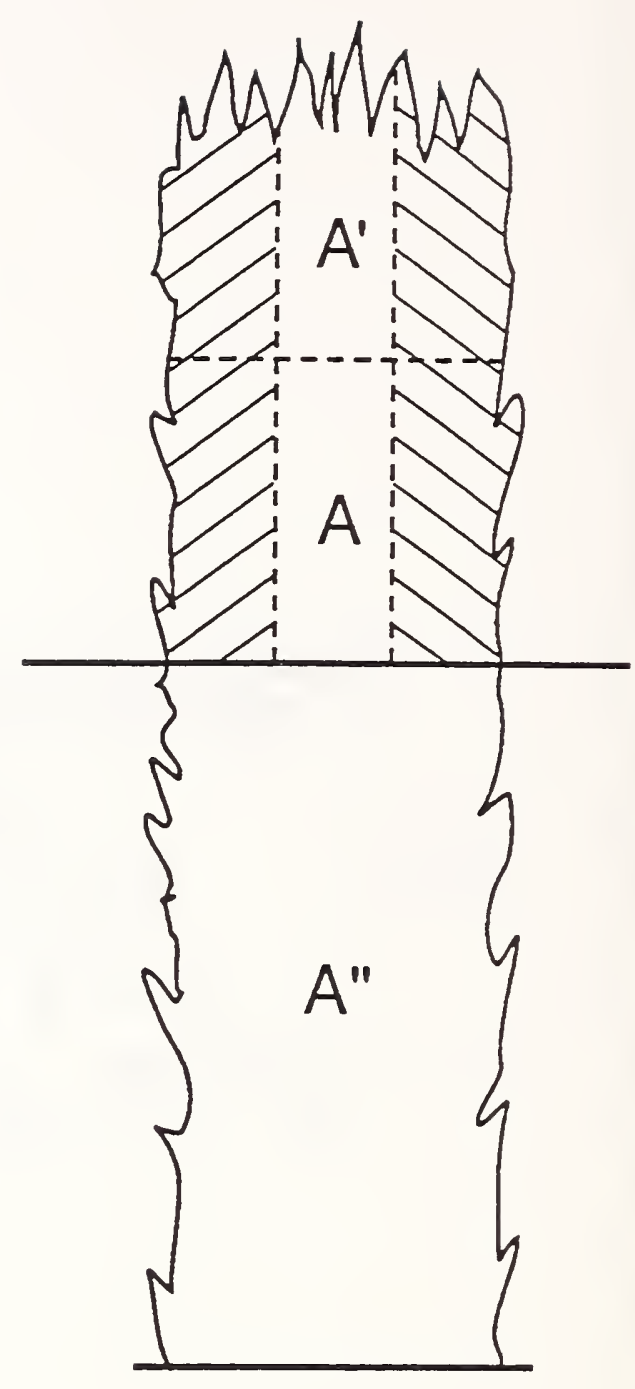

(b)

Figure 14a. Schematic, similar to figure 7. $\mathrm{C}$ and C' are the luminous (flame) regions within the central jet. $\mathrm{C}$ is the pyrolyzing region, when the ceiling is flammable (it has zero area when the ceiling is inert). B and B' are the analogous regions in the arms.

Figure 14b. A and A' are the zones for the virtual wall fire which are used to model the actual fire; that is, from which we can infer the fire strength and spread rate for configuration (a). A" is the actual pyrolyzing area on the wall. The shaded areas are explained in the text (Section 5.2). 


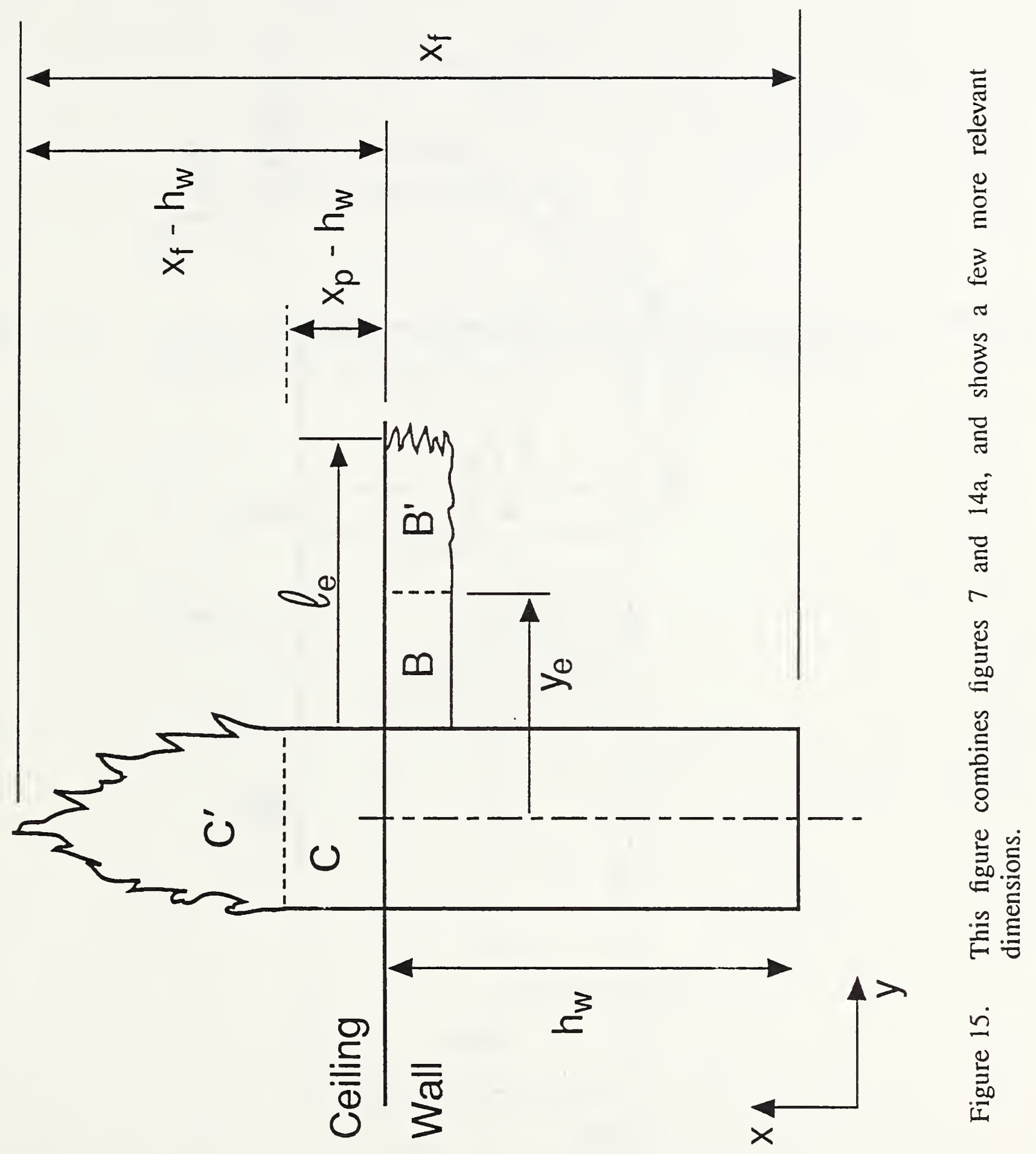




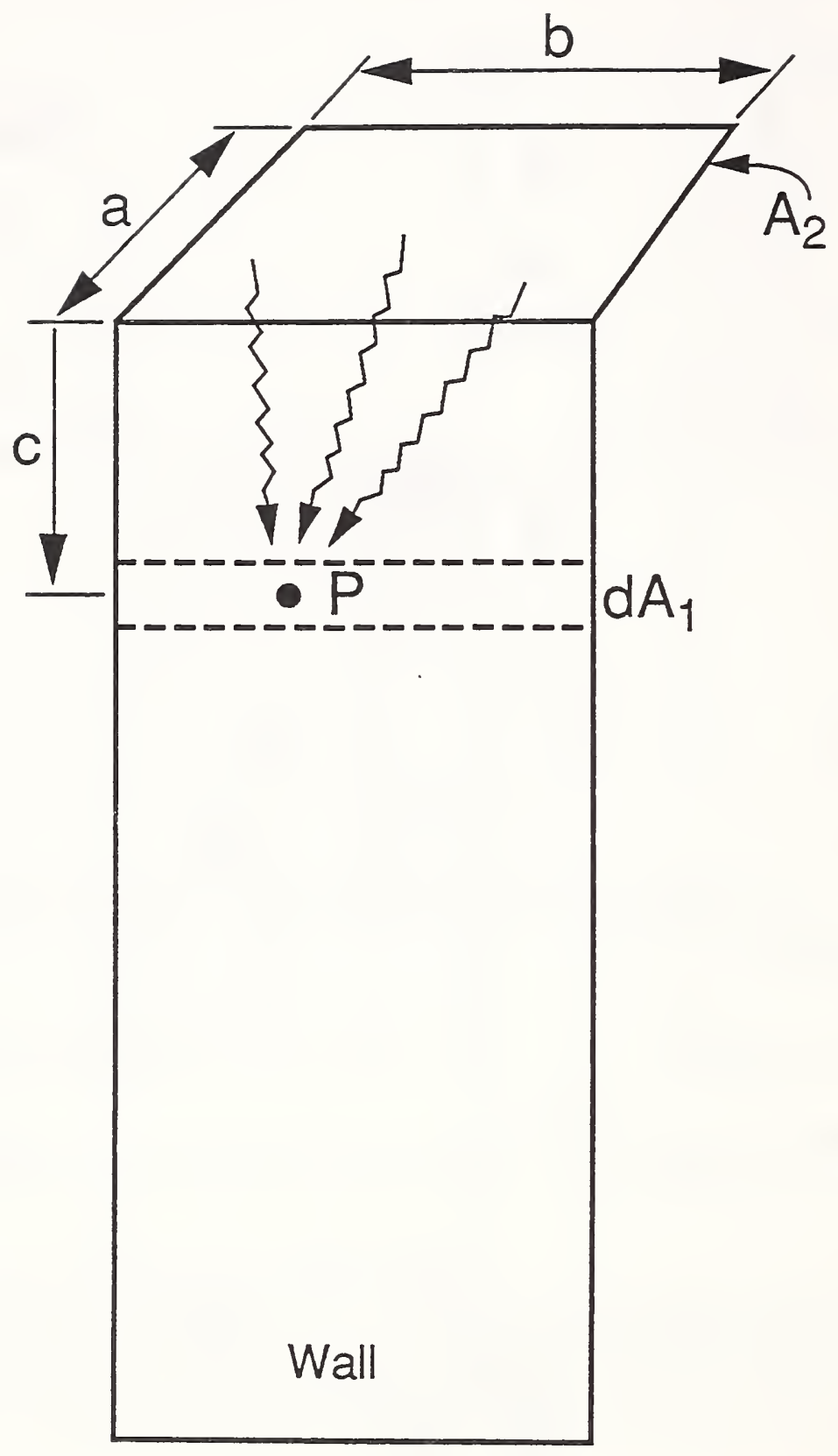

Figure 16. Schematic showing the geometry for the calculation of the view factor at point $P$ and for the strip running through $P$, from the luminous area $A_{2}$. 


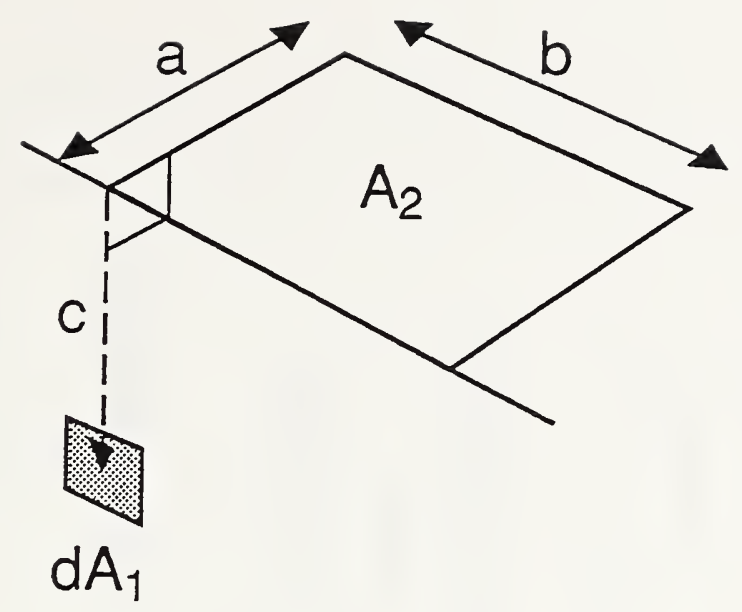

Figure 17. Configuration similar to that shown in figure 16, but applying to the differential element $d_{1}$ at the edge of region $A_{2}$, rather than the entire strip.

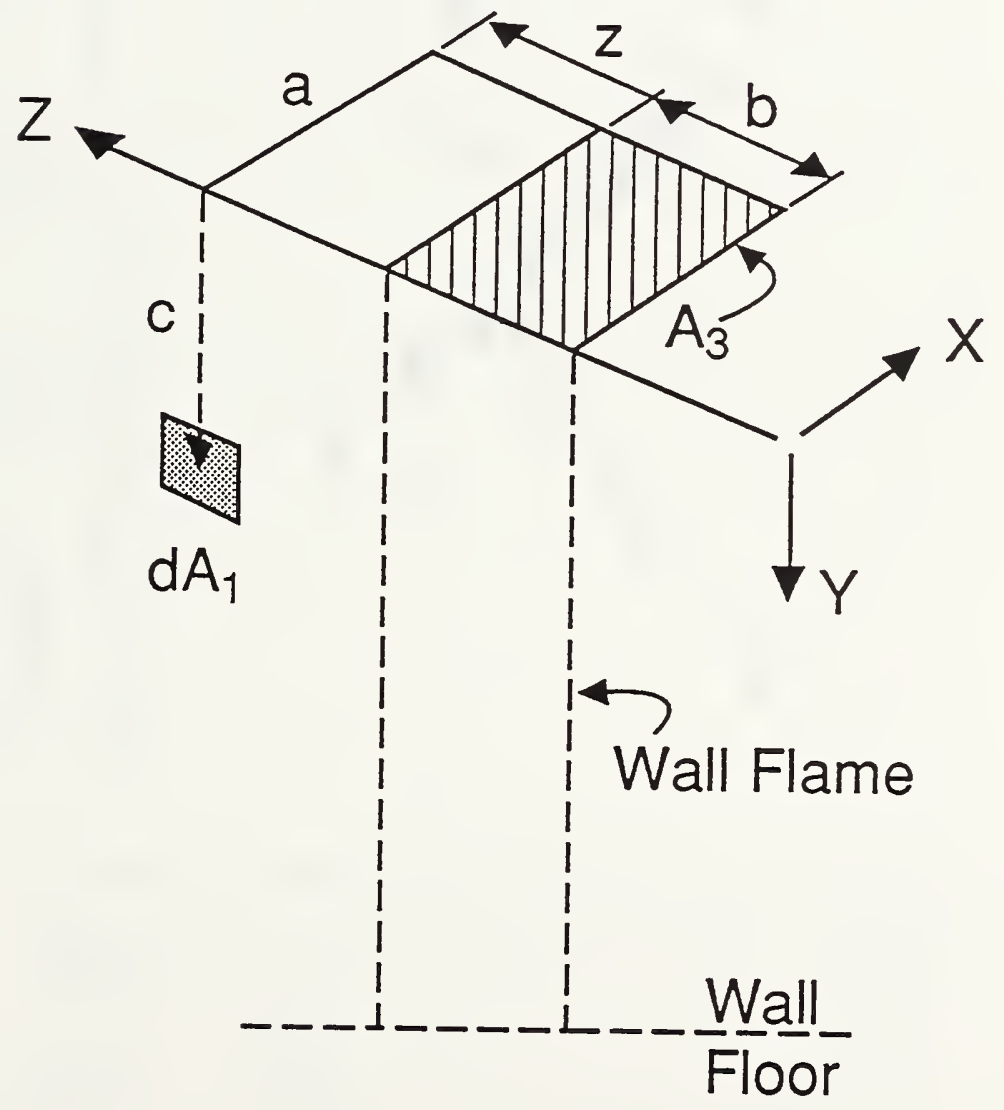

Figure 18. Applying the view factors found from figure 17 twice, we find the view factor for a point on the wall under the arm, located a distance $z$ "downstream" from $A_{2}$ and a distance $c$ down from the ceiling. 


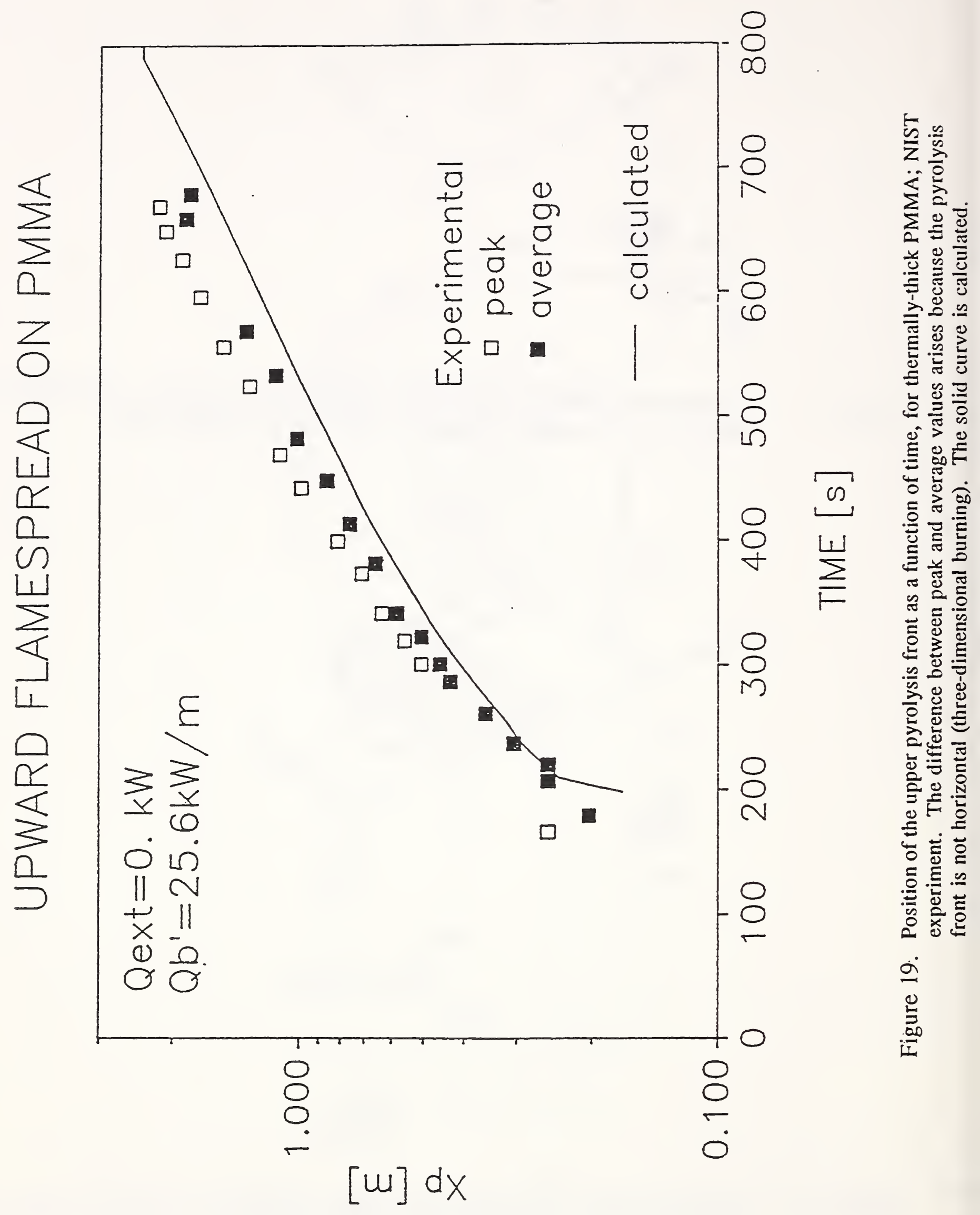




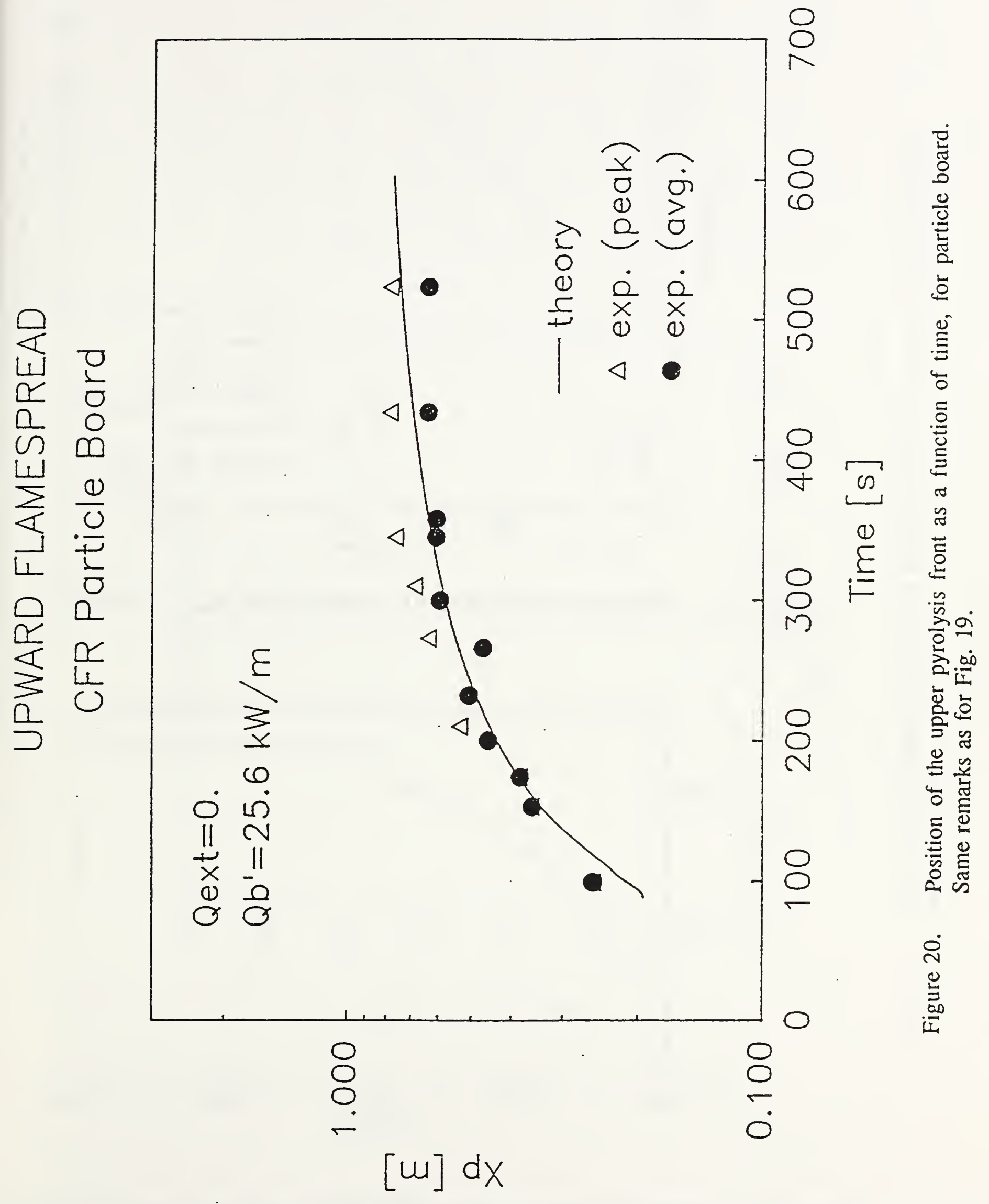




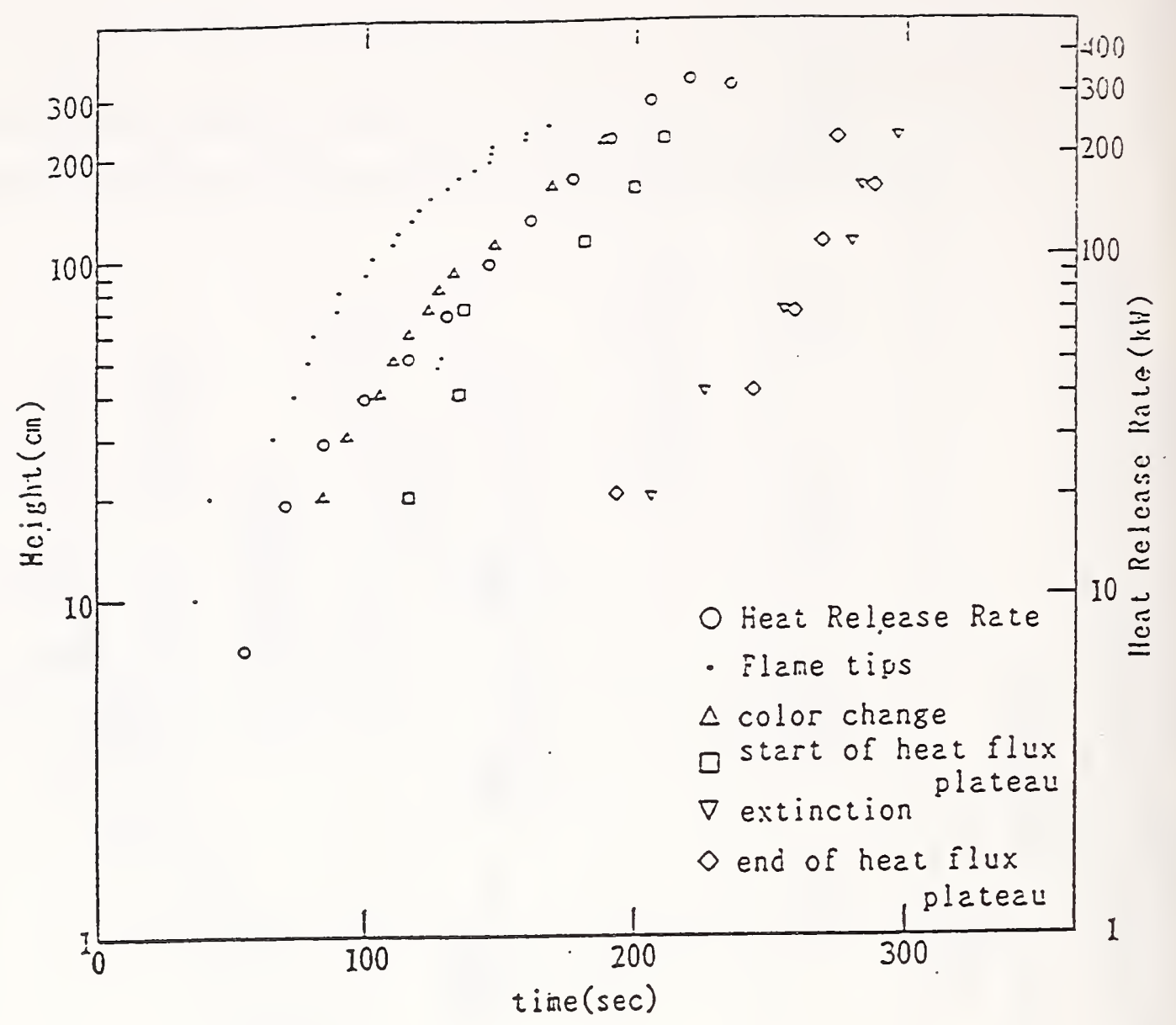

Figure 21a. Summary of experiment \#17 (particle board, $\phi_{\text {ext }} \approx 5 \mathrm{~kW} / \mathrm{m}^{2}$ ).

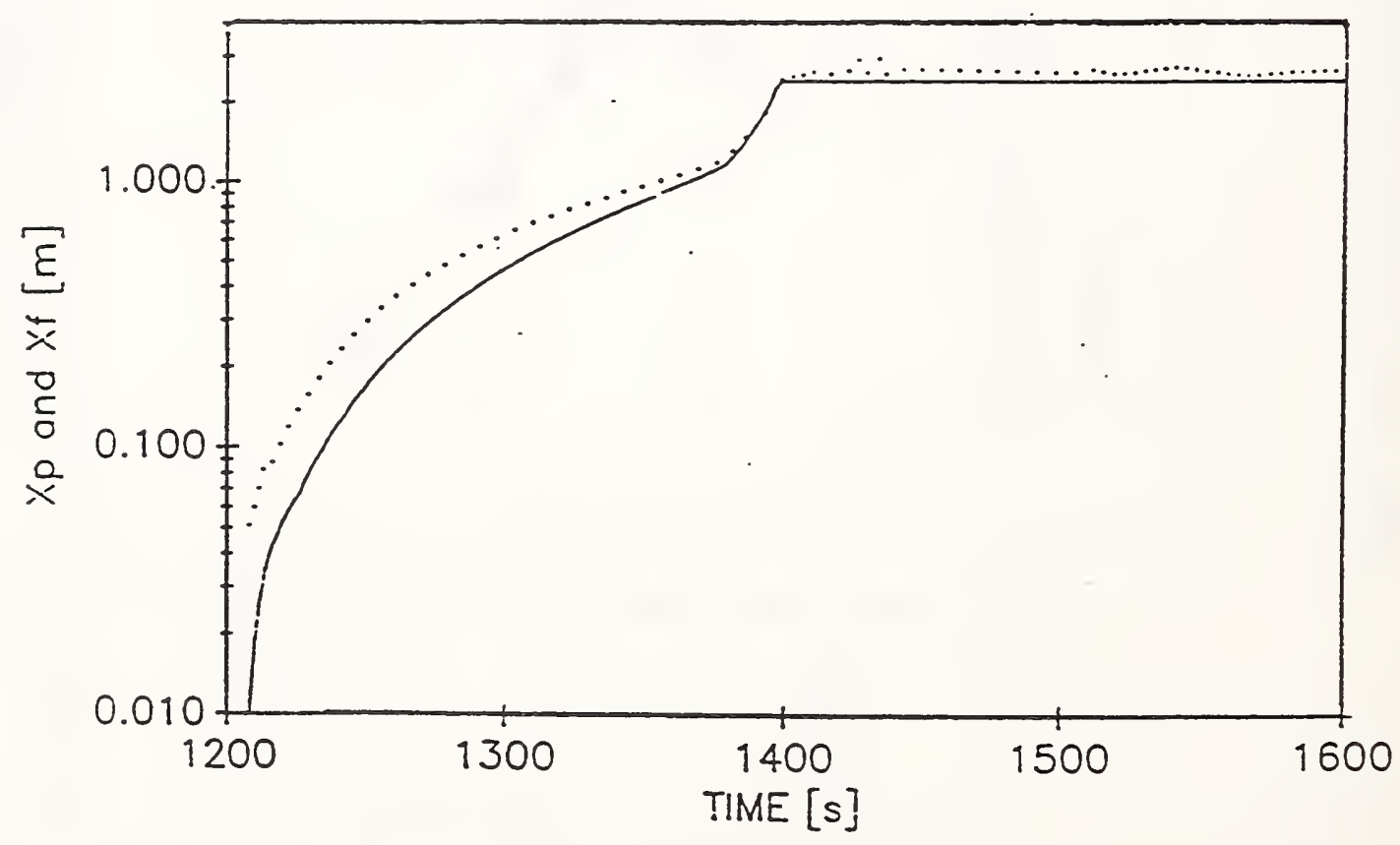

Figure 21b. Calculated values of pyrolysis front height (solid curve) and of flame-tip heights (dotted curve). 


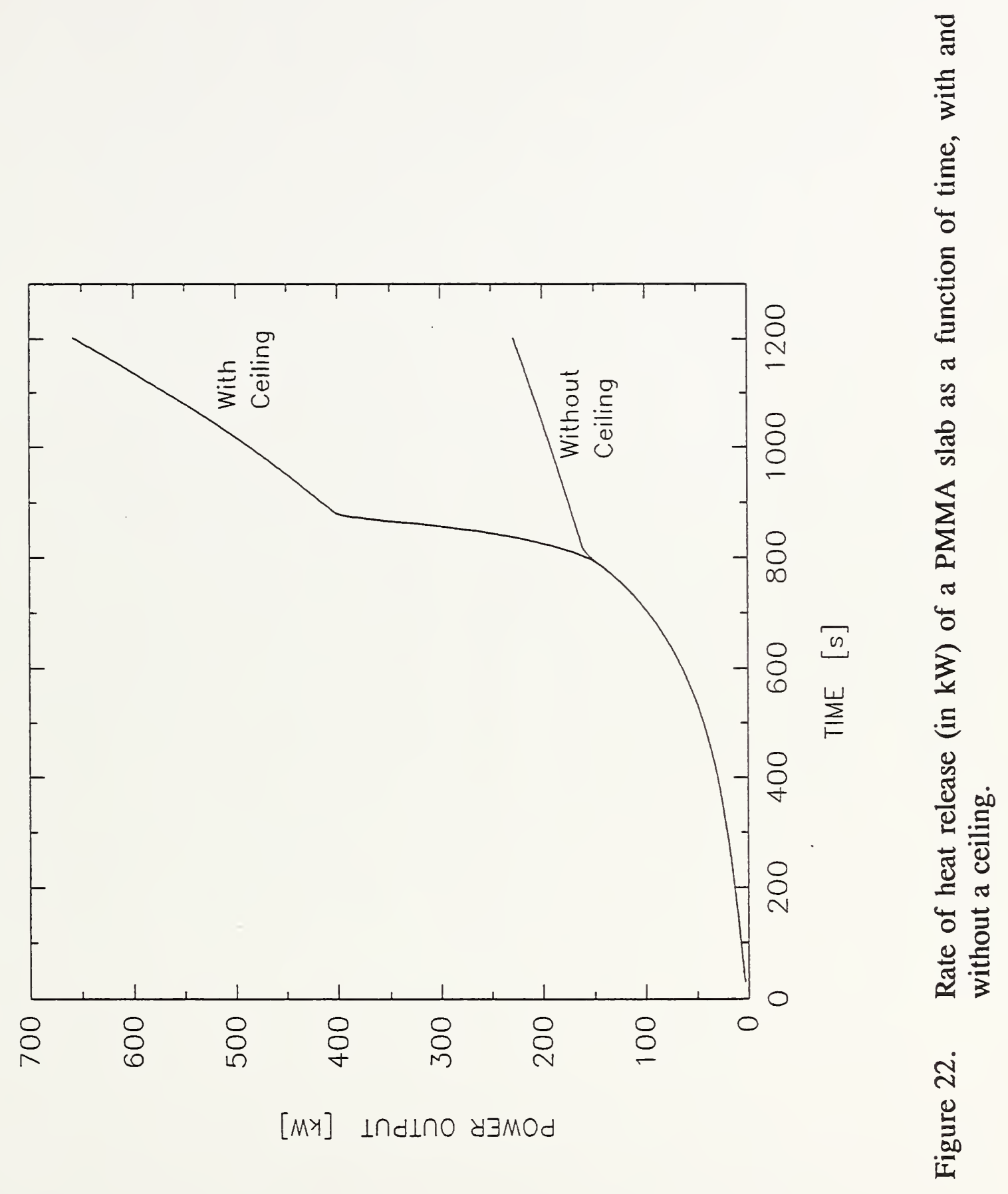




